\title{
Structure-deactivation relationships in zeolites during the methanol-to-hydrocarbons reaction: complementary assessments of the coke content
}

Daniel Rojo-Gama ${ }^{a}$, Matteo Signorilec, Francesca Boninoc, Silvia Bordiga ${ }^{c}$, Unni Olsbye ${ }^{a}$, Karl Petter Lillerud $^{\mathrm{a}}$, Pablo Beato ${ }^{\mathrm{b}}$, Stian Svelle ${ }^{\mathrm{a}}$

${ }^{a}$ Center for Materials Science and Nanotechnology (SMN), Department of Chemistry, University of Oslo, P.O. Box 1033, Blindern, N-0315 Oslo, Norway

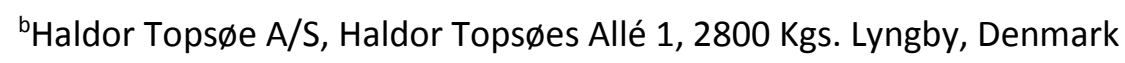

'Department of Chemistry, NIS and INSTM Reference Centre, University of Turin, Via G. Quarello 15, I-10135 and Via P. Giuria 7, I-10125, Turin, Italy

Corresponding authors:

Professor Stian Svelle

e-mail: stian.svelle@kjemi.uio.no

Phone: +47 22855454

Dr. Pablo Beato

e-mail: pabb@topsoe.dk

Phone: +45 45272000 


\begin{abstract}
Catalyst deactivation during the methanol-to-hydrocarbons (MTH) reaction was investigated using five different commercially prepared microporous catalysts, including Mordenite, ZSM-22, ZSM-5, zeolite Beta and SAPO-34. The reaction was carried out in a fixed bed reactor at a constant feed rate per gram of catalyst. Deactivated and partially deactivated catalysts were obtained at increasing reaction times. The whole of the catalyst beds were characterized using nitrogen adsorption, thermogravimetric analysis, a dissolution-extraction protocol, and UV-Raman spectroscopy, focusing primarily on methods suitable for the quantification of the coke. The results illustrate that topology is the dominant parameter that influences not only catalyst lifetime and product distribution, but also the nature of the species causing the deactivation. For all catalyst topologies, when the entire catalyst bed is examined together, the micropore volume and BET surface area decrease more rapidly than total coke from TGA increases at short reaction times. In the materials with the more restricted access to the internal voids, such as ZSM-22 and SAPO-34, the loss of activity is to a large extent due to species which are soluble in dichloromethane and give rise to distinct features in the Raman spectra. For the Mordenite and Beta catalysts, which have larger pores comprising three dimensional networks, and to some extent for the ZSM-5 catalyst employed, the accumulation of more coke species which are insoluble in dichloromethane, presumably on the external surface of the zeolite crystals, is observed. This is linked to the appearance of more pronounced $D$ and $G$ bands in the Raman spectra, indicative of extended carbon species.
\end{abstract}

\title{
Keywords
}

Zeotype; MTH; topology; TGA; UV-Raman; deactivating species; carbonaceous residues 


\section{Introduction}

The catalytic conversion of methanol to hydrocarbons (MTH) over acidic microporous catalysts is a versatile process, which, depending on the reaction conditions as well as the catalyst used, can yield a mixture of hydrocarbons suitable for use as high octane gasoline [1, 2]. Several variants of the process exist, such as the UOP/Norsk Hydro Methanol to Olefins (MTO) process, Mobil's Methanol to Gasoline (MTG) process, the Lurgi Methanol to Propylene Process (MTP), or Topsøe's Improved Gasoline Synthesis (TIGAS), and are in operation or are currently being commercialized $[3,4]$. The catalysts, zeolites or zeotypes, are crystalline materials with strong Brønsted acidity dispersed within well-defined pore and cavity structures of molecular dimensions. These features make the materials suitable as catalysts for the MTH reaction. It is currently established that aromatic species and/or alkenes located within the pore systems act as reaction intermediates and autocatalytic species in the hydrocarbon pool mechanism [3].

An important issue in the MTH process is that the zeolite catalyst activity decreases with time due to the accumulation of hydrocarbon residues. The MTG and MTP catalyst, ZSM-5, is sufficiently stable to warrant fixed bed operation, whereas SAPO-34, the MTO catalysts, is used in a fluidized bed with continuous regeneration due to more rapid coking. Deactivation is a major hurdle for commercial use of most other zeolites as catalysts. Thus, there is an obvious need to study, and ultimately understand and control, zeolite deactivation by coking. However, the complex reaction mechanisms and autocatalytic nature of the MTH process makes any study of deactivation complicated, because species such as methylbenzenes, regarded as active species in certain catalysts such as in SAPO-34 and Beta zeolite [3], may work as deactivating species in other materials like in ZSM-22 [5]. Even so, the decay in zeolite activity has been addressed in extensive research in recent years [6-15]. By and large, the deposition of coke is a reversible process, because when deactivated catalysts are treated in oxidative atmosphere at elevated temperatures, the coke is burnt off. Nevertheless, after certain number of regeneration cycles, zeolites lose the activity, and thus, the catalyst needs to be replaced. However, such irreversible deactivation is not the focus of this study.

Zeolite topology influences severely the type of hydrocarbon residues formed in the MTH reaction [3, 16-19]. Moreover, reaction temperature plays an important role on the formation of deactivating species. Olsbye et al. [14] recently evaluated the Gibbs energy of formation of different relevant molecules over a wide temperature range, and in agreement with investigations of ZSM-5 by Schulz [7], found that at mild reaction temperatures $\left(270-290^{\circ} \mathrm{C}\right)$ alkyl substituted benzene molecules cause the deactivation. At temperatures above $350{ }^{\circ} \mathrm{C}$, however, the alkylation-dealkylation equilibrium of 
benzene is shifted towards alkene formation, altering the mode of deactivation from the pore filling to external coking, as also highlighted by Bjørgen et al. [18].

Zeolite deactivation has been studied using different approaches, including the use of theoretical models [20-22], investigations of the influence of the physico-chemical properties in the deactivation $[10,13,23,24]$, and categorization according to the influence of volumes at channel intersections [17]. Special attention has been paid to the influence of cavity sizes indifferent topologies [19, 25-30]. In all these studies, the experimental approach was to deactivate severely or completely the catalysts followed by post-mortem studies by a variety of methods. Fewer studies focus on characterization of the evolution of hydrocarbon residues in zeolite catalysts with increasing reaction time or extent of deactivation [31, 32].

Guisnet and Magnoux [33] investigated the mode of coking and deactivation during the cracking of nheptane using USHY, Mordenite, ZSM-5 and Erionite. Parameters such as pore size, existence or nonexistence of cavities, and the dimensions of the channels varied among the zeolites used. It was concluded that during $n$-heptane cracking, the retention of coke was due to trapping at the channel intersections or in the cavities. The deactivation did not occur by acid site poisoning. Rather, the deactivation was initiated by limiting the access of reactants into the micropores followed by a blockage of the access to the active sites, regardless the zeolite topology.

In a key contribution, zeolite deactivation by coking during the MTH reaction in a fixed bed reactor has been described in a conceptual manner as a "burning cigar" by Haw and co-workers [34]. Briefly, Haw suggests that once the inlet part of the catalyst bed is active (i.e. a sufficient concentration of hydrocarbon pool species has been built up), a band of active catalyst moves downstream, leaving deactivated catalyst in its wake [34]. Later, this concept was further supported by Schulz [7]. By showing photos of partially deactivated catalyst beds, it was demonstrated that the inlet part of the catalyst bed was black, followed by a bluish section, where coke seeds are formed exclusively from the olefin products [7]. The spatiotemporal deactivation of ZSM-5 [23] and SAPO-34 [35, 36] in fixed bed reactors has also been investigated using a variety of laboratory methods and synchrotron techniques. Very recently, Lercher and co-workers [6] placed these concepts on a more mechanistic foundation. By comparing fixed bed and CSTR reactors, it was concluded that the methanol concentration was relevant for the deactivation of catalysts in MTO conversion [6]. This has been linked to the formation of formaldehyde (a compound leading to rapid deactivation), and it has been suggested that this reaction requires Lewis acid sites [37].

In this work, the evolution of deactivating species is studied in 5 different catalysts, 4 aluminosilicate zeolites and one silicoaluminophosphate zeotype, as a function of MTH reaction time. Rather than 
relying on model materials, all the catalysts investigated have been supplied by commercial zeolite manufacturers (except the SAPO-34, which has been synthesized according to the patent literature [38]). This approach was chosen to make probable that the materials studied reflect the behavior of actual, commercial catalysts. The topologies of the catalysts used in this contribution are described and shown in S.1 (Supplementary Material). For each topology, a series of catalysts with increasing degree of deactivation were obtained. Subsequently, the partially deactivated catalysts were characterized using nitrogen adsorption, thermogravimetric analysis, a dissolution-extraction protocol, and UV-Raman. Profound differences in the mode of deactivation is found among the catalysts, as it appears that the diffusion restricted systems (SAPO-34 and ZSM-22) tend to accumulate molecular coke species to a significant extent, whereas the ZSM-5 and in particular the Mordenite, and Beta catalysts suffer from the formation of more extended coke species.

\section{Experimental}

\subsection{Catalyst preparation}

In the current work, with the exception of SAPO-34, all catalysts were commercially available. Mordenite (composition given by manufacturer is $\mathrm{Si} / \mathrm{Al}=11$; manufacturer's code is 14-386) was supplied by Ventron. ZSM-22 $(\mathrm{Si} / \mathrm{Al}=50)$ and Beta $(\mathrm{Si} / \mathrm{Al}=15 ; \mathrm{CP} 806)$ were acquired from Zeolyst International and ZSM-5 (Si/AI = 14; MFI-27) by Süd-Chemie.

The SAPO-34 material was synthesized as follows: A mixture of phosphoric acid, ( $85 \%$, Merck), tetraethyl ammonium hydroxide (TEAOH, 35\%, Sigma Aldrich) and deionized water was prepared. The mixture was heated to $30^{\circ} \mathrm{C}$ and Ludox-AS-40 (40\% $\mathrm{SiO}_{2}$, DuPont) and Pural SB (76\% $\left.\mathrm{Al}_{2} \mathrm{O}_{3}, \mathrm{SASOL}\right)$ were added under continuous stirring before aging at $30{ }^{\circ} \mathrm{C}$ for $2 \mathrm{~h}$ under stirring. The molar ratio of the final gel was $0.3 \mathrm{SiO}_{2}: 1 \mathrm{Al}_{2} \mathrm{O}_{3}: 1 \mathrm{P}_{2} \mathrm{O}_{5}: 1 \mathrm{TEAOH}: 35 \mathrm{H}_{2} \mathrm{O}$. The aged gel was transferred to Teflonlined autoclaves and heated to $165^{\circ} \mathrm{C}$ with a heating rate of $5{ }^{\circ} \mathrm{C} / \mathrm{h}$, and maintained at $165^{\circ} \mathrm{C}$ for $72 \mathrm{~h}$ with rotation. The reaction was quenched in water and the product was separated by centrifugation. The product was washed well with deionized water and dried at $95{ }^{\circ} \mathrm{C}$ overnight.

All materials were ion-exchanged three times for 2 hours, using a $1 \mathrm{M}$ solution of $\mathrm{NH}_{4} \mathrm{NO}_{3}$ at $65{ }^{\circ} \mathrm{C}$. The ion-exchanged zeolites were further calcined in static air at $550^{\circ} \mathrm{C}$ for 5 hours to desorb ammonia, thereby obtaining the materials in their protonic form. 


\subsection{Catalyst characterization}

\subsubsection{Characterization of fresh catalysts}

The chemical composition of the fresh catalysts was measured using a Microwave Plasma Atomic Emission Spectrometer (MP-AES 4100) from Agilent Technologies. $50 \mathrm{mg}$ of zeolite was dissolved in 1 $\mathrm{mL} 15$ wt\% hydrofluoric acid for 30 minutes in a home-made Teflon ${ }^{\circledR}$ vial. The dissolved zeolite was transferred to a $50 \mathrm{~mL}$ polypropylene volumetric flask containing $0.15 \mathrm{~g}$ of boric acid to neutralize remaining hydrofluoric acid. The flask was subsequently filled with deionized water.

Powder X-Ray Diffraction (XRD) patterns for the fresh catalysts were recorded using a Siemens Bruker D500 instrument in Graff-Brentano geometry with $\mathrm{Cu} \mathrm{K} \alpha_{1}$ radiation $(\lambda=1.5406 \AA$ ). The purity and crystallinity of the samples were further studied by LeBail refinement method, which allows us to characterize the properties of the material by extracting the intensities from the powder diffraction data and fits the parameters by least squares minimization process $[39,40]$.

The size and morphology of zeolite particles were analyzed with Scanning Electron Microscopy (SEM). Micrographs were recorded on a Hitachi SU 8230 FE-SERM. Uncoated samples in powder form were glued on the holder with carbon tape.

The BET surface areas and pore volumes were determined by using $\mathrm{N}_{2}$ physisorption at $77 \mathrm{~K}$ using a Belsorp-mini II instrument. Fresh catalysts were outgassed under vacuum for 5 hours; 1 hour at $80^{\circ} \mathrm{C}$ followed by a period of 4 hours at $300{ }^{\circ} \mathrm{C}$. The BET surface areas were determined based on linear fitting of the data in the $p / p_{0}$ range of 0.01-0.1 [41]. Two approaches were used to determine the micropore volumes. First, the standard t-plot approach was used, which is suitable for materials displaying isotherms types I and IV [42]. Second, the micropore volume was estimated from the $\mathrm{N}_{2}$ uptake at a relative pressure $p / p_{0}=0.2$, converting the gas uptake to the equivalent liquid volume. This second approach is introduced primarily due to difficulties in applying the t-plot method to partially deactivated catalysts with low pore volumes.

The acid site accessibility, concentration and speciation on the fresh catalysts were characterized with Fourier Transform Infrared (FT-IR) spectroscopy, using CO and pyridine as probe molecules. A Bruker Vertex 80 instrument with a Mercury Cadmium Telluride (MCT) detector was employed, using a resolution of $2 \mathrm{~cm}^{-1}$. An in-house designed transmission cell with $\mathrm{KBr}$ windows was used. Catalysts were prepared as thin wafers supported in a gold envelope and pre-treated in vacuum $\left(<10^{-5} \mathrm{mbar}\right)$ for 3 hours: 1 hour at $150{ }^{\circ} \mathrm{C}$ followed by 1 hour at $300{ }^{\circ} \mathrm{C}$ and finally 1 hour at $450{ }^{\circ} \mathrm{C}$. CO was dosed and the sample was cooled down to $-196^{\circ} \mathrm{C}$ using liquid nitrogen. Then, spectra were recorded during CO desorption by evacuation.

Pyridine was used as probe molecule to determine the concentration of acid sites. Bands at 1544 and $1455 \mathrm{~cm}^{-1}$ are assigned to pyridine adsorbed on Brønsted (pyridinium ions) and Lewis acid sites, 
respectively [43]. Despite its trustable quantitative meaning, due to its strong basicity, pyridine is not able to distinguish among different Lewis sites: the $1455 \mathrm{~cm}^{-1}$ band is in fact reported as a feature of any kind of aluminum-pyridine complexes (both with isolated or oxidic phases) [43, 44]. Conversely, the weaker CO probe could discriminate among different Lewis sites [45, 46]. After having performed the experiment using $\mathrm{CO}$ as probe molecule, samples were reactivated at $450^{\circ} \mathrm{C}$ under vacuum and then cooled down to room temperature. The adsorption of pyridine was done by exposing the pellets to the vapor pressure of pyridine. Spectra were recorded while excess pyridine was desorbed, and the samples were considered to be saturated when no differences between two consecutive spectra was observed. Then, catalysts were heated to $200{ }^{\circ} \mathrm{C}$ for 2 hours, to remove the physisorbed species, and the final spectrum, used for quantitative measurement, was recorded. The Integrated Molar Extinction Coefficient (IMEC) used in this work is reported elsewhere [43]. As the dimensions of the pore openings in SAPO-34 (3.8 $\mathrm{A} \times 3.8 \AA$ ) are smaller than the kinetic diameter of pyridine (5.4 $\AA$ ) [47], the experiment with pyridine was not carried out for this catalyst.

\subsubsection{Characterization of deactivated catalysts.}

As mentioned, the MTH reaction was carried out for increasing reaction times for each catalyst topology, in order to generate five series of partially deactivated catalyst samples. For example, for Mordenite, nine increasingly deactivated catalyst samples were obtained (reaction times 5, 10, 15, $20,30,40,45,60$, and 75 minutes, where the longest reaction time corresponds to a completely deactivated catalyst). These partially deactivated catalysts were characterized to determine the amount and nature of the deactivating species in each topology.

The BET surface area was determined using the same equipment as for the fresh catalysts; however, the samples were pre-treated differently to prevent the removal of coke from the catalysts. After investigating the influence of pre-treatment conditions (Supplementary Material Figure S.10), it was found that outgassing for $1 \mathrm{~h}$ at $80^{\circ} \mathrm{C}$ followed by 3 hours at $200{ }^{\circ} \mathrm{C}$ was sufficient for the partially deactivated samples. The micropore volume was estimated from the $\mathrm{N}_{2}$ uptake at a relative pressure $\mathrm{p} / \mathrm{p}_{0}=0.2$.

According to Bibby [48], the amount of "internal" coke can be estimated from the reduction in pore volume, assuming that this reduction corresponds to coke compounds with a certain density. Such an analysis was carried out also here, but yielded unreasonable results (the "internal" coke content was greater than the total coke from TGA). Further details can be found in the Supplementary Material. What will be referred to as the total coke content was measured with thermogravimetric analysis (TGA) using a Rheometric Scientific STA 1500 instrument. Typically, 15 mg of catalyst was heated to 
$600{ }^{\circ} \mathrm{C}$ in a flow of synthetic air using a heating rate of $5^{\circ} \mathrm{C} \mathrm{min}-1$ and a hold time of 40 min at $600{ }^{\circ} \mathrm{C}$. Total coke is given in wt\% relative to the regenerated catalyst (final mass in the TGA profiles).

Soluble coke species were determined following the Guisnet method [49]. Approximately $15 \mathrm{mg}$ of deactivated sample was dissolved in small Teflon ${ }^{\circledR}$ vials using $1 \mathrm{~mL} 15 \% \mathrm{HF}$ during $60 \mathrm{~min}$. The addition of $1 \mathrm{~mL}$ of $\mathrm{CH}_{2} \mathrm{Cl}_{2}$ with ortho-chloro-toluene as internal standard, allowed the extraction of the soluble fraction of coke, which was subsequently analyzed and quantified by GC-MS. An Agilent $7890 \mathrm{GC}$ with a HP5-MS column ( $60 \mathrm{~m}, 0.25 \mathrm{~mm}$ i.d, stationary phase thickness $0.25 \mu \mathrm{m}$ ) connected to an Agilent 5975 mass spectrometer was used in the analysis. The oven temperature was increased from $50{ }^{\circ} \mathrm{C}$ to $300{ }^{\circ} \mathrm{C}$ with a heating rate of $10^{\circ} \mathrm{C} \mathrm{min}^{-1}$ (hold time 3 minutes at $50{ }^{\circ} \mathrm{C}$ and 15 minutes at $300{ }^{\circ} \mathrm{C}$ ). For compound identification, the NIST98 database was used. The relative amount of soluble coke relative to the total coke from TGA was estimated. Details on the calibration required for this analysis are available in the Supplementary Material.

UV-Raman spectra of deactivated catalysts were collected on a Renishaw inVia Raman Microscope spectrometer, equipped with a 3600 lines $/ \mathrm{mm}$ grating to disperse the scattered light on a UV enhanced, Peltier cooled CCD detector. The excitation beam was focused on the sample through a $15 \times$ long working distance objective. The Rayleigh peak was removed by a dielectric edge filter. A Coherent MotoFred $300 \mathrm{C}$ frequency doubled $\mathrm{Ar}^{+}$laser, emitting at $244 \mathrm{~nm}$, was used as excitation source. In order to exploit the full power of the laser on the samples (about $5 \mathrm{~mW}$ ) without beam induced damage, the measurements were performed with continuous rotation of the samples, exploiting the features of an in-house designed cell [50]. Twenty spectra were collected for each sample, verifying that no variation (i.e. decomposition) occurred during the measurements. Samples were measured in air in pellet form.

\subsection{Catalytic tests}

Catalytic experiments were performed using $100 \mathrm{mg}$ of sample in a continuous down-flow fixed bed U-shaped quartz reactor with an internal diameter of $10 \mathrm{~mm}$. In each experiment, the catalyst powder was pressed, crushed and sieved, and the particle fraction between 250 to $420 \mu \mathrm{m}$ was used to avoid pressure build-up. Prior to reaction, catalysts were heated to $550{ }^{\circ} \mathrm{C}$ in He flow. At this temperature, catalysts were calcined in situ for 1 hour using a flow of pure $\mathrm{O}_{2}$.

The methanol to hydrocarbon reaction was performed at atmospheric pressure and $400{ }^{\circ} \mathrm{C} .19 .5 \mathrm{~mL}$ $\mathrm{min}^{-1}$ of $\mathrm{He}$, used as carrier gas, was bubbled through a methanol saturator ( $\mathrm{MeOH}$ supplied by BDH Laboratory $>99,8 \%$ purity) kept at a temperature of $20{ }^{\circ} \mathrm{C}$, giving rise to a methanol partial pressure of 130 mbar, resulting in a WSHV of $2 \mathrm{~g}_{\mathrm{MeOH}} \mathrm{g}_{\text {catalyst }}{ }^{-1} \mathrm{~h}^{-1}$. The temperature in the catalyst bed was measured with a stainless steel sheathed thermocouple placed inside the reactor. Reaction products 
were analyzed online using an Aglient 6890 A GC with a Flame lonization Detector (FID). The equipment has a Supelco SPB-5 capillary column with dimensions of $60 \mathrm{~m} \times 0.53 \mathrm{~mm} \times 3 \mu \mathrm{m}$. Conversion, selectivities and product yields were calculated as reported elsewhere [17]..

The MTH reaction was thermally quenched at increasing reaction times, thereby generating a series of increasingly deactivated catalysts for each topology. As the catalyst lifetime differs among topologies, initial tests until total deactivation served to choose appropriate reaction times to quench the reaction. When the predefined reaction time was reached, the $\mathrm{MeOH}$ flow was switched to $\mathrm{He}$, the reactor was rapidly lifted out of the oven and the catalyst was subsequently removed from the reactor tube. 


\section{Results}

\subsection{Characterization of fresh catalysts.}

The X-ray diffractograms with full-profile Le Bail analysis are summarized in Figure S.2 (Supplementary Material), confirming that the samples are highly crystalline and have the expected structure [51]. In the case of H-Beta, the observed diffraction peaks are particularly broad. Such peak broadening is due to the fact that Beta is a disordered intergrowth structure, composed of three different polymorphs. Moreover, the very small crystal size evident from the micrographs in Figure S.3 might contribute to such broadening of the reflections.

Table 1 outlines the main characterization results for the fresh catalysts. For the commercial catalysts, the measured $\mathrm{Si} / \mathrm{Al}$ ratios correspond well to those provided by the respective manufacturers. For practical reasons, Mordenite, ZSM-5 and Beta samples with high aluminum content were selected, in order to shorten the catalytic lifetime [52-58]. For SAPO-34, the composition, and thus density of acid sites, is assumed to be in accordance with the composition of the synthesis gel. The (Al+P)/Si ratio corresponds to one silicon atom per cage, i.e. one Brønsted acid site per cage. It is a complicating factor that the catalysts have preferred compositional ranges which do not necessarily overlap.

The quantitative analysis with FT-IR and pyridine shows that the Mordenite, ZSM-22, and ZSM-5 catalysts primarily are Brønsted acidic, as expected. For the Beta catalyst, however, a large fraction of Lewis acidity is measured. It is also clear that for Mordenite, a large fraction of the Al present does not contribute to acidity measurable with pyridine. 
Table 1. Key characteristics of the catalysts studied.

\begin{tabular}{|c|c|c|c|c|c|c|c|c|c|c|}
\hline Sample & $\begin{array}{l}\text { Si/Al } \\
\text { ratio }^{a}\end{array}$ & $\begin{array}{c}\mathrm{Al} \\
\text { concentration } \\
(\mathrm{mmol} / \mathrm{g})^{\mathrm{a}}\end{array}$ & $\begin{array}{c}\text { BAS } \\
\text { concentratio } \\
\mathrm{n}(\mathrm{mmol} / \mathrm{g})^{\mathrm{c}}\end{array}$ & $\begin{array}{c}\text { LAS } \\
\text { concentratio } \\
\mathrm{n}(\mathrm{mmol} / \mathrm{g})^{\mathrm{c}}\end{array}$ & $\begin{array}{c}\text { BET } \\
\text { area } \\
\left(\mathrm{m}^{2} \mathrm{~g}-\right. \\
1)\end{array}$ & $\begin{array}{l}\text { External } \\
\text { area } \\
\left(\mathrm{m}^{2} \mathrm{~g}-{ }^{-1}\right)\end{array}$ & $\begin{array}{l}\text { Total } \\
\text { pore } \\
\text { volume } \\
\left(\mathrm{cm}^{3} \mathrm{~g}^{-1}\right)\end{array}$ & $\begin{array}{l}\text { Micropor } \\
\text { e volume } \\
\left(\mathrm{cm}^{3} \mathrm{~g}^{-1}\right)\end{array}$ & $\begin{array}{l}\text { Particle } \\
\text { size } \\
(\mu \mathrm{m})\end{array}$ & $\begin{array}{c}\Delta v\left((\mathrm{OH}) \mathrm{cm}^{-1}\right) \\
\text { upon } \mathrm{CO} \\
\text { adsorption }\end{array}$ \\
\hline Mordenite & 8 & 1.85 & 0.71 & 0.07 & 498 & 4 & 0.19 & 0.19 & $2-6$ & 310 \\
\hline ZSM-5 & 15 & 1.04 & 0.95 & 0.06 & 414 & 5 & 0.18 & 0.17 & $1-4$ & 328 \\
\hline Beta & 17 & 0.93 & 0.39 & 0.54 & 677 & 190 & 0.99 & 0.19 & $<1$ & 311 \\
\hline SAPO-34 & $11^{\mathrm{b}}$ & - & - & - & 708 & 5 & 0.34 & 0.27 & $<1$ & 277 \\
\hline
\end{tabular}
a. From MP-AES.
b. $(\mathrm{Al}+\mathrm{P}) / \mathrm{Si}$ in the gel.
c. Pyridine adsorption.

The textural properties obtained using $\mathrm{N}_{2}$-sorption (isotherms given in Figure S.4), reveal that with the exception of Beta zeolite, all the catalysts are purely microporous, with values of BET surface area and pore volumes in agreement with those previously reported $[16,17,31]$. For the Beta zeolite, the external surface area represents approximately the $30 \%$ of the total BET area. This high value might be linked to the small particle size of the crystallites. The high external surface area, high concentration of Lewis acidity, and the relatively low amount of Brønsted acid sites detected with FTIR using $\mathrm{CO}$ as a probe molecules (see Figure S.8), indicates that a significant fraction of the $\mathrm{Al}$ is located on the external surface instead of in the catalyst framework for this zeolite. This might influence the deactivation behavior of this particular catalyst sample.

The crystal morphology of the catalysts was investigated by SEM. The Mordenite sample shows highly agglomerated crystals of size between 1 and $6 \mu \mathrm{m}$. The ZSM-22 displays a similar particle size distribution as seen for Mordenite, but the particles have the needle-like morphology which is typical for this topology. ZSM-5 and SAPO-34 crystals grow in their characteristic coffin shape (1-4 $\mu \mathrm{m})$ and cubic $(<1 \mu \mathrm{m})$ morphology respectively. For Beta, well defined crystals are not discernable in the SEM images.

A measure of the Brønsted acid site strength is obtained by evaluating the shift in the vibrational frequency of the hydroxyls when using $\mathrm{CO}$ as probe molecule. Even though there are substantial differences in the $\mathrm{Si} / \mathrm{Al}$ ratios of the catalysts, the results observed for the four aluminosilicates are very similar and in the expected range $[47,59-61]$, indicative of a similar acid site strength. For the 
silicoaluminophosphate SAPO-34, the shift, and correspondingly the acid strength, is markedly lower as expected $[54,62,63]$.

\subsection{Catalyst performance and characterization of deactivated catalyst samples}

As mentioned earlier, in this work we have generated partially deactivated samples at increasing times on stream. First, an experiment until total deactivation was performed with each catalyst to evaluate the overall catalyst lifetime. Subsequently, we chose suitable reaction times to follow the deactivation specifically for each catalyst topology. In the following figures, the conversion of methanol for each such experiment is shown with different colors to highlight the excellent reproducibility. After each separate catalytic test, the partially deactivated catalysts were characterized with $\mathrm{N}_{2}$ adsorption, TGA, and dissolution-extraction experiments to quantitatively assess the evolution of the textural properties and to determine the amount of hydrocarbon species built up, respectively. Already at this point, it should be emphasized that it is the whole catalyst bed which has been analyzed. This means that the data shown correspond to an average, disregarding the axial distribution of coke along the bed, which has been documented by e.g. Bleken [23], Schulz [7], Haw and co-workers [64], and Luo et al. [65]. What then might appear as an evolution with respect to time is actually a change in the average degree of coke deposition over the catalyst bed, making reaction time an unreliable independent variable in this study. This means that the focus here will be on the major differences observed among the topologies. This limitation might be alleviated to some extent by separating the catalyst bed into segments $[23,66]$ or by using methods that allow spatial resolution $[35,67]$. However, this does not constitute a fundamental solution, as this would require the layer analyzed to be infinitesimally thin. Recently, progress was made using a CSTR, which is inherently gradient free [6]. It was shown, however, that the deactivation mechanism can be strongly influenced by choice of reactor [6]. One could consider using a fluidized bed reactor, but this is not straightforward. It should also be noted that industrially, the MTG process is carried out in fixed bed reactors at appreciable conversions. Altogether, this means that the focus here will be on the major differences observed among the topologies. 


\subsubsection{Mordenite}

The catalytic performance of the Mordenite catalyst is summarized in Figure 1 and in the Supplementary Material where product selectivites are shown. Note that the conversion data in the left panel of Figure 1, which is a composite of several repeated experiments, follow exactly the same profile. The major features are in agreement with those previously reported [52,68]. At these conditions, the initial methanol conversion is $100 \%$, accompanied by a high yield of the lower olefins $\left(C_{2}\right.$ and $\left.C_{3}\right)$ at the shortest reaction times. Methanol breakthrough occurs quite early, approximately after 20 minutes on stream. Following the breakthrough of methanol, the conversion decreases rapidly. Rapid deactivation is expected for a high Al Mordenite [52]. The heaviest hydrocarbon detected in the effluent is hexamethylbenzene. A fair amount of methane is detected in the effluent, again indicative of rapid deactivation. Methane is thought to be formed directly from the dehydrogenation and disproportionation of dimethyl ether or methanol during the initial stages of reaction $[69,70]$, but also from the dealkylation of polymethylbenzenes or coke molecules as suggested by Guisnet and co-workers [71].

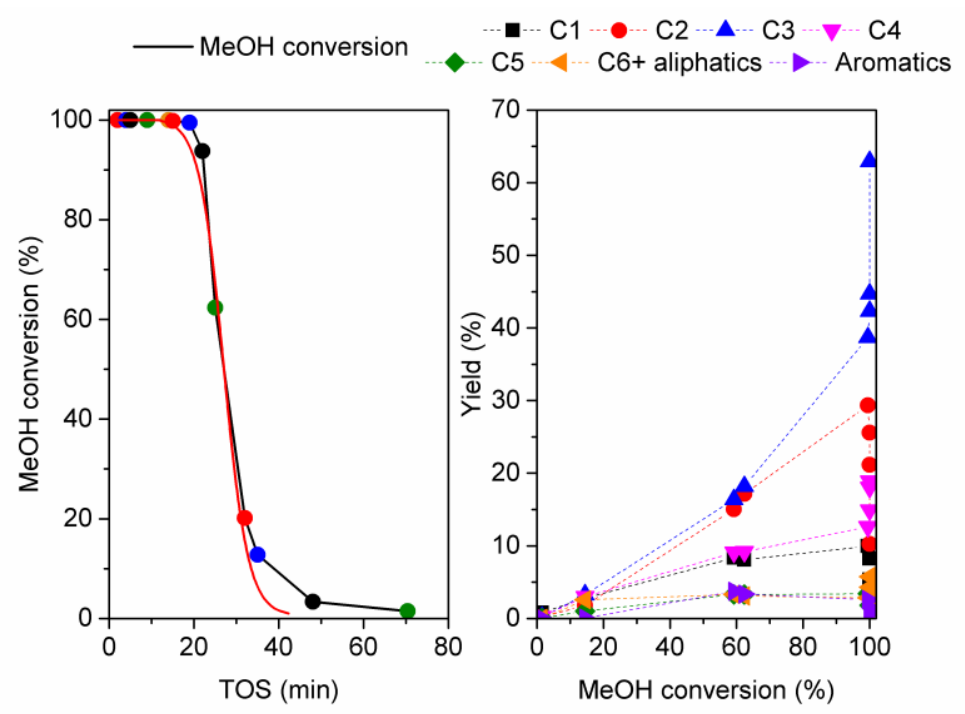

Figure 1. Conversion of methanol to hydrocarbons over Mordenite at $400{ }^{\circ} \mathrm{C}$ and WHSV $=2 \mathrm{gg}-1 \mathrm{~h}-1$. Left panel: Methanol conversion versus time on stream; differently colored symbols correspond to different experiments. Right panel: Product yield as a function of methanol conversion. C2, C3, C4 and C5 refer to the sum of both alkenes and alkanes for each carbon number. This holds throughout. The full red line shows the simulated deactivation profile, see section 4.1

Table 2 summarizes the characterization of the increasingly deactivated catalyst as a function of time on stream for Mordenite. Clearly, deactivating species start to form at the very beginning of the reaction. After only 5 minutes on stream, coke was detected by TGA and after 20 minutes on stream, immediately before the methanol breakthrough, the total coke amount corresponds to $85 \%$ of the maximum coke amount detected. A similar evolution is seen for the BET surface and micropore 
volume, but the reduction of these values is even more profound during the early stages of reaction. Beyond 20 minutes on stream, no micropore volume was accessible for the adsorption of $N_{2}$, suggesting a fast and complete filling and/or blocking of the micropores. It is particularly interesting to note that we were able to identify appreciable amounts of soluble coke species only at the shortest reaction times, reaching a maximum fraction of soluble species of $25 \%$ of the total coke at 10 minutes on stream. Following this, the solubility of the coke species decreases, and becomes negligible for the longest reaction times. As is clear when comparing Table 2 and Figure S.12, both the relative and absolute amount of soluble coke decrease with increasing reaction times. Previous work has shown that substituted pyrenes are the heaviest hydrocarbons detectable in the extracts generated by this approach [32]. From 40 minutes on stream and onwards the methanol conversion is very low and no further significant changes are seen in the data in Table 2.

Table 2. Characterization of the partially deactivated Mordenite samples.

MORDENITE

\begin{tabular}{cccccc} 
TOS (min) & $\begin{array}{c}\text { MeOH } \\
\text { conversion } \\
(\%)\end{array}$ & $\begin{array}{c}\text { Surface area } \\
\left(\mathrm{m}^{2} \mathrm{~g}^{-1}\right)^{\mathrm{a}}\end{array}$ & $\begin{array}{c}\text { Micropore } \\
\text { volume } \\
\left(\mathrm{cm}^{3} \mathrm{~g}^{-1}\right)\end{array}$ & $\begin{array}{c}\text { Coke } \\
\text { content }(\%)\end{array}$ & $\begin{array}{c}\text { Soluble coke } \\
\text { with respect } \\
\text { total coke }(\%)\end{array}$ \\
\hline 0 & - & 498 & 0.19 & - & - \\
5 & 100 & 460 & 0.19 & 0.5 & 14 \\
10 & 100 & 210 & 0.08 & 3.0 & 25 \\
15 & 100 & 81 & 0.03 & 7.2 & 6.9 \\
20 & 99 & 19 & 0.02 & 8.3 & 4.8 \\
30 & 32 & 4 & 0 & 9.7 & 3.6 \\
40 & 9 & 3 & 0 & 9.8 & 1.8 \\
45 & 6 & 4 & 0 & 9.9 & 2.5 \\
60 & 3 & 3 & 0 & 9.7 & 0.8 \\
75 & 1 & 2 & 0 & 9.7 & 1.0 \\
\hline
\end{tabular}

a. BET analysis.

b. Thermogravimetric experiment.

c. Dissolution-extraction experiment. 


\subsubsection{ZSM-22}

The catalyst performance of ZSM-22 is shown in Figure 2. In line with previous studies, this particular zeolite is characterized by having a relatively short lifetime [31, 72-74]. As shown, after 3 hours on stream this sample is totally deactivated. Moreover, ZSM-22 is also known to produce an aromaticfree product, as seen in the right panel of Figure 2, where the yield of aromatic species remain close to zero over the whole conversion range. This product distribution is obtained because this particular zeolite catalyzes the methanol conversion nearly exclusively via the alkene cycle branch [73] of the dual cycle mechanism $[18,75]$. The aromatic species located within the pores have been shown to be mostly inert towards alkene formation [73].

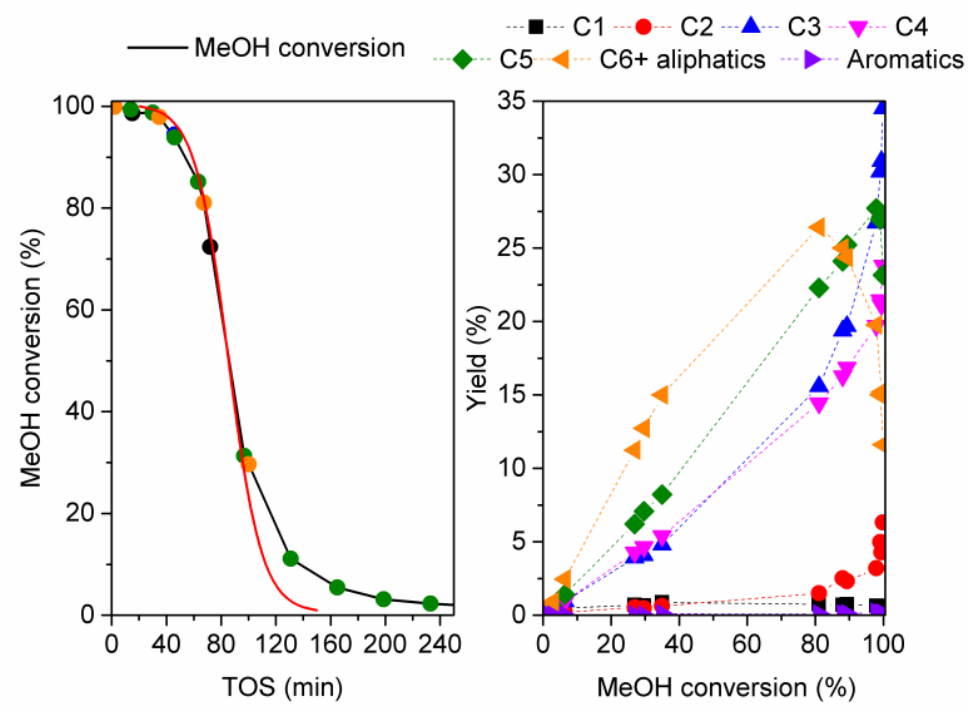

Figure 2. Conversion of methanol to hydrocarbons over ZSM-22 at $400{ }^{\circ} \mathrm{C}$ and WHSV $=2 \mathrm{gg}^{-1} \mathrm{~h}^{-1}$. Left panel: Methanol conversion versus time on stream; differently colored symbols correspond to different experiments. Right panel: Product yield as a function of methanol conversion.

Characterization results for the partially deactivated ZSM-22 samples are shown in Table 3. As was also seen for Mordenite, the BET surface area and micropore volume are quickly reduced, whereas the total coke accumulates somewhat more slowly. For example, at 30 minutes on stream, the surface area is reduced by $72 \%$ compared to the initial value, and the micropore volume by $62 \%$, whereas the total coke content at this reaction time constitutes $27 \%$ of the final, maximum value. Clearly, the final total coke content is lower for ZSM-22 than for Mordenite, by a factor close to 3 . This difference correlates well with the differences in surface area throughout the series of catalyst topologies (see section 4.2 below). Notably, ZSM-22 displays a quite appreciable and almost constant fraction of soluble species at different reaction times. Thus, the absolute amount of soluble coke increases concomitantly with the total coke content (Table 3 and Figure S.13). It is reasonable to 
assume that the major fraction of the soluble coke detected for ZSM-22 can be classified as "internal" coke, i.e. coke located in the micropores of the catalyst. The coke molecules are mainly napthalene and anthracene derivatives, which appear to reflect the linear, onedimensional pore system, as previously adressed using a combination of dissolution/extraction and XRD peak intensity analysis [76]. This issue is further discussed in section 4.5.

Table 3. Characterization of the partially deactivated ZSM-22 samples.

\begin{tabular}{|c|c|c|c|c|c|}
\hline \multicolumn{6}{|c|}{ ZSM-22 } \\
\hline $\begin{array}{c}\text { TOS } \\
\text { (min) }\end{array}$ & $\begin{array}{c}\mathrm{MeOH} \\
\text { conversion } \\
(\%)\end{array}$ & $\begin{array}{l}\text { Surface area } \\
\qquad\left(\mathrm{m}^{2} \mathrm{~g}-{ }^{1}\right)^{\mathrm{a}}\end{array}$ & $\begin{array}{l}\text { Micropore } \\
\text { volume } \\
\left(\mathrm{cm}^{3} \mathrm{~g}^{-1}\right)\end{array}$ & $\begin{array}{c}\text { Coke content } \\
(\%)^{b}\end{array}$ & $\begin{array}{l}\text { Soluble coke } \\
\text { with respect } \\
\text { total cokec }(\%)\end{array}$ \\
\hline 0 & - & 232 & 0.08 & - & - \\
\hline 30 & 99 & 65 & 0.03 & 0.8 & 30 \\
\hline 60 & 86 & 41 & 0.02 & 2.1 & 37 \\
\hline 75 & 67 & 33 & 0.01 & 2.5 & 37 \\
\hline 90 & 41 & 31 & 0.01 & 2.6 & 38 \\
\hline 120 & 17 & 22 & 0.01 & 2.7 & 41 \\
\hline 240 & 3 & 20 & 0.01 & 3.0 & 39 \\
\hline
\end{tabular}
a. BET analysis.
b. Thermogravimetric experiment.
c. Dissolution-extraction experiment.

\subsubsection{ZSM-5}

Figure 3 shows the conversion of methanol and product yield when the MTG archetype ZSM- 5 catalyst was used. Unlike most industrially applied ZSM-5 catalysts, that maintain full conversion for longer periods of time [77], a ZSM-5 with very high aluminum content, (Si/AI $=15)$ was employed here in order to shorten the experimental time of these studies. This ZSM-5 sample deactivates completely after 20 hours on stream, converting a total amount of $23 \mathrm{~g}_{\mathrm{MeOH}} \mathrm{g}_{\mathrm{cat}}{ }^{-1}$. Previous studies with regular and desilicated ZSM-5 catalysts have reported total conversion capacities ranging from similar values up to more than $1000 \mathrm{~g}_{\mathrm{MeOH}} \mathrm{g}_{\mathrm{cat}}{ }^{-1}[20,77,78]$. Despite the rapid deactivation, the product yields are unremarkable and typical for this catalyst topology [14]. 


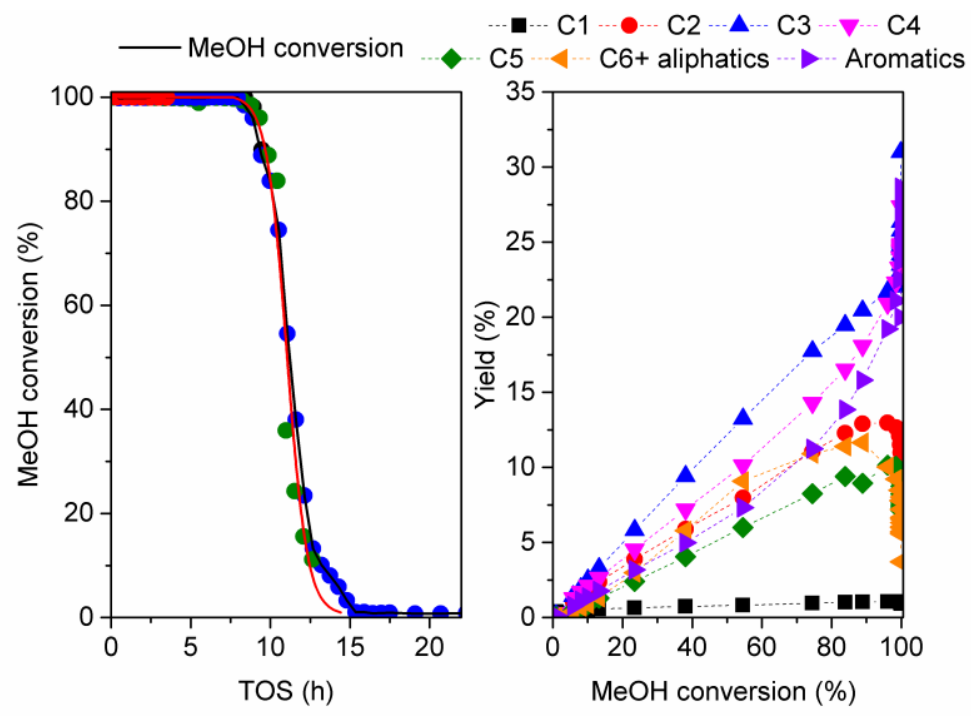

Figure 3. Conversion of methanol to hydrocarbons over ZSM-5 at $400{ }^{\circ} \mathrm{C}$ and WHSV $=2 \mathrm{gg}^{-1} \mathrm{~h}^{-1}$. Left panel: Methanol conversion versus time on stream; differently colored symbols correspond to different experiments. Right panel: Product yield as a function of methanol conversion.

In contrast to Mordenite and ZSM-22, the ZSM-5 catalyst maintains full conversion for several hours before methanol breakthrough. It is therefore possible to analyze the data presented in Table 4 for characterization of the partially deactivated catalysts according to two stages, i.e. before and after methanol breakthrough. Looking first at the total coke content, this appears to increase linearly with time on stream until methanol breakthrough, after which a levelling off in the rate of coke accumulation is seen. Similar observations have been made by McLellan et al [79]. This can be explained if the rate of deactivation is assumed to be proportional to the degree of methanol conversion, as suggested by Janssens [20] (see section 4.5 below). For the BET surface area and micropore volume, on the other hand, a large reduction is seen already at 4 hours on stream, followed by a linear decrease with time throughout the remainder of the experiment. Thus, after methanol breakthrough, a complete reduction in micropore volume accompanied by a slight increase in the total coke content is seen. This is in line with the hypothesis of Bibby [80], who discusses that the formation of deactivating species initially occurs in the microporous channels and at a later stage more profoundly on the surface of the crystals. The fraction of soluble coke might appear to reach a maximum just before the breakthrough of methanol, but a definitive conclusion is not warranted, as the uncertainty of these values is significant. Inspection of Figure S.14 reveals that the absolute amount of soluble coke is relatively stable after methanol breakthrough. Previous work has shown that the amount of soluble coke becomes insignificant for severely deactivated ZSM- 5 catalysts (Si/AI $=13$ to 140$)[17,18,81]$. It should be pointed out that the chromatograms of the coke extracts derived from this catalyst differ somewhat from previous investigations. Typical ZSM-5 coke extracts 
(Si/Al ratios ranging from 13 to 140 ) contain primarily methylbenzenes $[17,18,81]$, whereas for this particular catalyst, bi- and trinuclear polyaromatics are seen. Thus, the detection of these compounds here cannot be unequivocally attributed to the very high aluminum content. However, an alternative cause is presently not apparent.

Table 4. Characterization of the partially deactivated ZSM-5 samples.

\begin{tabular}{|c|c|c|c|c|c|}
\hline \multicolumn{6}{|c|}{ ZSM-5 } \\
\hline TOS (h) & $\begin{array}{c}\mathrm{MeOH} \\
\text { conversion } \\
(\%)\end{array}$ & $\begin{array}{l}\text { Surface area } \\
\qquad\left(m^{2} g^{-1}\right)^{a}\end{array}$ & $\begin{array}{c}\text { Micropore } \\
\text { volume }\left(\mathrm{cm}^{3} \mathrm{~g}^{-1}\right)\end{array}$ & $\begin{array}{c}\text { Coke content } \\
(\%)^{b}\end{array}$ & $\begin{array}{l}\text { Soluble coke } \\
\text { with respect } \\
\text { total } \operatorname{coke}^{\mathrm{c}}(\%)\end{array}$ \\
\hline 0 & - & 414 & 0.17 & - & - \\
\hline 4 & 100 & 237 & 0.09 & 3.8 & 8.9 \\
\hline 8 & 100 & 144 & 0.06 & 6.5 & 13 \\
\hline 10 & 84 & 87 & 0.04 & 7.8 & 27 \\
\hline 13 & 11 & 9 & 0 & 9.0 & 23 \\
\hline 20 & 0 & 5 & 0 & 9.7 & 21 \\
\hline
\end{tabular}
a. BET analysis.
b. Thermogravimetric experiment.
c. Dissolution-extraction experiment.

\subsubsection{Beta}

The catalyst performance of the Beta zeolite is summarized in Figure 4. The catalyst lifetime is moderate, and a product spectrum rich in aromatics (up to hexamethylbenzene), propane, and isobutane is seen, in agreement with previous reports [16, 81]. Inspection of the left panel of Figure 4 reveals that the reproducibility in the conversion data is somewhat less good for this catalyst compared to the others. However, the reproducibility is still considered to be acceptable. 


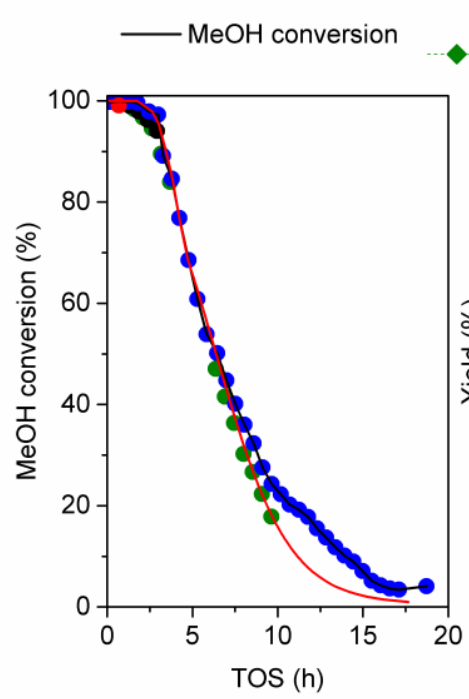

$\square \mathrm{C} 1 \cdots \mathrm{C} 2 \cdots \mathbf{\Delta} \cdots \mathrm{C} 3 \cdots \boldsymbol{\nabla} \cdot \mathrm{C} 4$

- C5 4 C6+ aliphatics $\cdots$ Aromatics

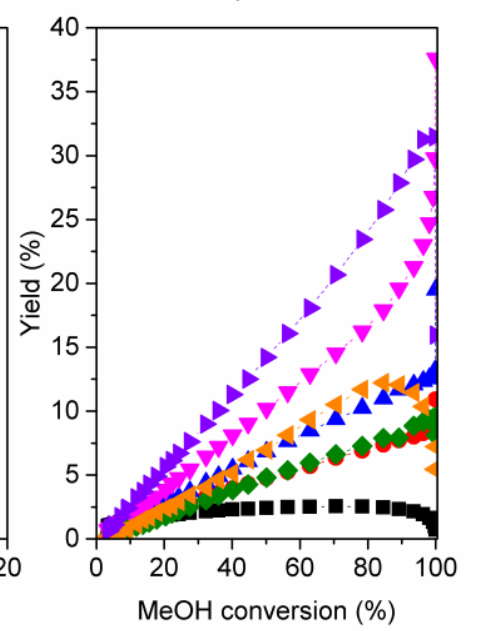

Figure 4. Conversion of methanol to hydrocarbons over zeolite Beta at $400{ }^{\circ} \mathrm{C}$ and WHSV $=2 \mathrm{gg}^{-1} \mathrm{~h}^{-1}$. Left panel: Methanol conversion versus time on stream; differently colored symbols correspond to different experiments. Right panel: Product yield as a function of methanol conversion.

Characterization results for the partially deactivated Beta samples are shown in Table 5. Overall, the picture is similar to that seen for the catalysts discussed so far: Reductions in micropore volume and BET surface area and significant coke deposition is seen already at a very early stage. However, it appears that for zeolite Beta, these parameters follow each other more closely. For ZSM-22, it was highlighted that the BET surface area and micropore volume was reduced faster than the deposition of coke and the behavior is similar for Mordenite and ZSM-5. For Beta, on the other hand, the percentagewise reduction in pore volume and surface area is virtually identical to the percentage of coke formed (relative to the final, total amount of coke). This might, however, be an artefact resulting from the remaining porosity seen for this sample even when fully deactivated and not an indication of a fundamentally different behavior (see section 4.5 below). It appears that the remaining BET surface area is related to the significant external surface area (Table 1) seen for this sample. Presumably, the interparticle voids giving rise to the measured external surface of the fresh catalyst are not filled or blocked by coke species. Notably, the residual micropore volume is much smaller than the residual BET surface area. A fairly high amount of total coke is seen, reaching a maximum of $17 \mathrm{wt} \%$ for the completely deactivated sample. Finally, the fraction of soluble coke is always small for the Beta catalyst, and both the relative and absolute amount of compounds detectable in the extracts is eventually diminished upon increasing deactivation (Figure S.15). 
Table 5. Characterization of the partially deactivated Beta samples.

\begin{tabular}{cccccc}
\hline \multicolumn{2}{|c|}{ BETA } & & & \\
\hline $\begin{array}{c}\text { TOS } \\
(\mathrm{h})\end{array}$ & $\begin{array}{c}\text { MeOH } \\
\text { conversion } \\
(\%)\end{array}$ & $\begin{array}{c}\text { Surface area } \\
\left(\mathrm{m}^{2} \mathrm{~g}^{-1}\right)^{\mathrm{a}}\end{array}$ & $\begin{array}{c}\text { Micropore } \\
\text { volume }\left(\mathrm{cm}^{3} \mathrm{~g}^{-1}\right)\end{array}$ & $\begin{array}{c}\text { Coke content } \\
(\%)^{\mathrm{b}}\end{array}$ & $\begin{array}{c}\text { Soluble coke with } \\
\text { respect total coke } \\
(\%)\end{array}$ \\
\hline 0 & - & 678 & 0.19 & - & - \\
1 & 99 & 442 & 0.12 & 6.1 & 3.0 \\
2 & 98 & 412 & 0.10 & 7.4 & 1.3 \\
4 & 81 & 306 & 0.06 & 10.8 & 1.1 \\
6 & 57 & 273 & 0.05 & 12.1 & 1.3 \\
10 & 22 & 205 & 0.03 & 15.2 & 0.8 \\
19 & 3 & 175 & 0.02 & 17.0 & \\
\hline
\end{tabular}
a. BET analysis.
b. Thermogravimetric experiment.
c. Dissolution-extraction experiment.

\subsubsection{SAP0-34}

The last material investigated in this study is SAPO-34, the catalyst employed commercially in the MTO process. As observed in Figure $5, C_{2}$ and $C_{3}$ products dominate, owing to the pore structure of this catalysts, which consists of big cavities and narrow-pore windows, which allow only the lightest product to diffuse out. The major part of the catalyst activity is lost after 20 hours on stream, but it appears that the methanol conversion approaches $0 \%$ very slowly after this. Such a residual activity has been observed previously [54, 82].

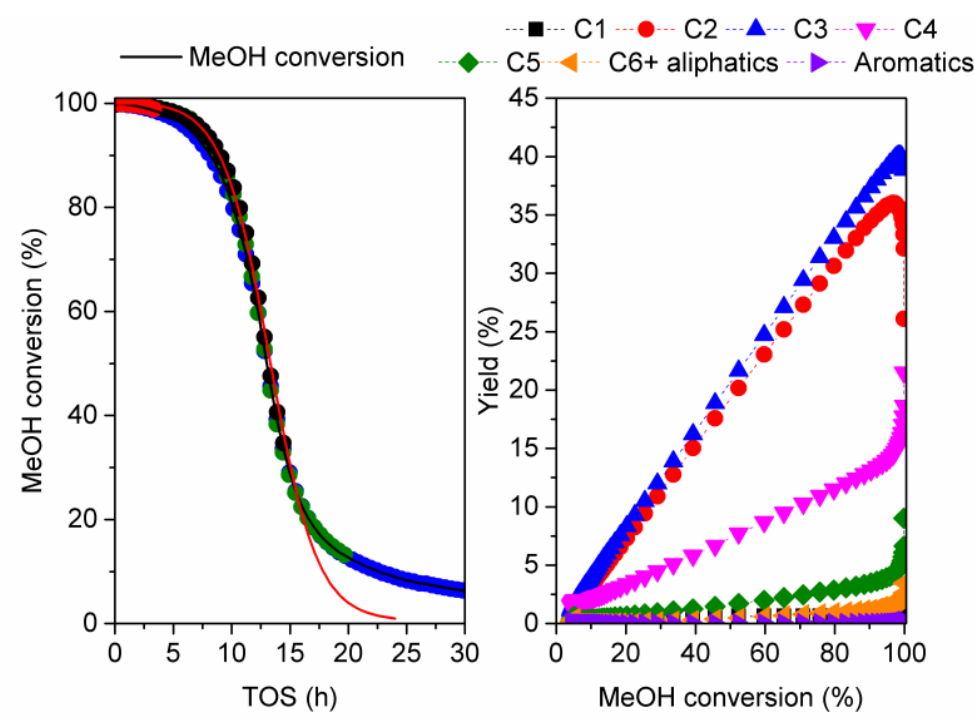

Figure 5. Conversion of methanol to hydrocarbons over SAPO-34 at $400{ }^{\circ} \mathrm{C}$ and WHSV $=2 \mathrm{gg}^{-1} \mathrm{~h}^{-1}$. Left panel: Methanol conversion versus time on stream; differently colored symbols correspond to different experiments. Right panel: Product yield as a function of methanol conversion. 
Characterization data for partially deactivated SAPO-34 catalysts are shown in Table 6. During the first four hours of reaction, corresponding to the first data point, the micropore pore volume and surface area was significantly reduced by approximately $60 \%$ compared to that of the fresh catalyst, whereas the total coke deposited corresponded to $25 \%$ of the final, maximum value. Following this initial step, a more simultaneous reduction in surface/pore volume and increase in total coke was seen. After 15 hours on stream, the surface area and micropore volume were negligible. Even so, the total amount of coke continued to increase, despite the low methanol conversion values. This growth in the total content of coke is attributed to reactions between species trapped in the cages of this material with the incoming methanol, generating, heavier, more condensed and more stable species [32]. Chromatograms obtained in the dissolution-extraction experiment (Figure S.16) show that substituted naphthalene compounds are detected in the internal structure even at the shortest reaction time. In line with previous results [27], a shift towards heavier aromatic species is observed at longer experiments, with substituted pyrenes as the largest aromatic species trapped in the internal zeolite structure. By using a combination of XRD, theoretical methods, and dissolution/extraction, Zokaie et al. [83] were able to demonstrate that substituted pyrenes fit into the SAPO-34 cages. These fairly large molecules are substantially deformed when adsorbed, and their accumulation lead to an expansion primarly of the c-axis of the unit cell. SAPO-34 shows the largest amount of soluble coke among the five catalysts investigated, decreasing slightly with reaction time from 52 to $40 \%$ of the total coke. The absolute amount of soluble coke increases monotonously with reaction time (see Figure S.16).

Table 6. Characterization of the partially deactivated SAPO-34 samples.

\begin{tabular}{cccccc}
\hline \multicolumn{2}{|c|}{ SAPO-34 } & \multicolumn{1}{c}{ Surface area } \\
TOS (h) & $\begin{array}{c}\text { MeOH } \\
\text { conversion (\%) }\end{array}$ & $\begin{array}{c}\text { Micropore volume } \\
\left(\mathrm{m}^{2} \mathrm{~g}^{-1}\right)^{\mathrm{a}}\end{array}$ & $\begin{array}{c}\text { Coke content } \\
\left.(\%)^{-1}\right)\end{array}$ & $\begin{array}{c}\text { Soluble coke } \\
\text { with respect } \\
\text { total cokec }(\%)\end{array}$ \\
\hline 0 & - & 708 & 0.27 & - & - \\
4 & 99 & 293 & 0.11 & 5.4 & 52 \\
8 & 91 & 179 & 0.07 & 10.9 & 45 \\
15 & 35 & 32 & 0.01 & 17.2 & 40 \\
20 & 13 & 15 & 0 & 18.7 & 43 \\
30 & 5 & 8 & 0 & 21.2 & 40 \\
\hline
\end{tabular}
a. BET analysis
b. Thermogravimetric experiment.
c. Dissolution-extraction experiment. 


\section{Discussion}

\subsection{To which extent can the catalysts be compared?}

To establish further comparisons among samples, we analyzed the conversion curves according to the deactivation model proposed by Janssens [20]. This kinetic model yields a deactivation coefficient $(a)$, the rate constant $(k)$, and the total conversion capacity $\left(R_{0}\right)$. The deactivation coefficient, (a) corresponds to the amount of catalyst (or number of active sites) lost when a mol of reactant is transformed into hydrocarbons, i.e. how rapidly the catalyst is deactivated. The rate constant, (k) gives the activity of the catalyst in millimoles of methanol converted per acid site per hour, and the conversion capacity (obtained from these two values) gives the total amount of methanol converted to hydrocarbon per acid site until complete deactivation. This quantity may also be obtained in a model independent manner by integration of the conversion curves (the left panels of Figures 1-5). The data thus obtained is listed in Table 7. The simulated deactivation profiles based on Janssens' two parameter model are shown as full red lines in Figures 1-5. In general, good agreement with the experimental profile shape is achieved, despite the simplicity of the model. The inverse S-shaped curves suggest that the reactant methanol is involved in reactions leading to coke formation. Furthermore, the tail observed in the experimental curves at low conversion suggests that also product-product reactions contribute to coke formation [14].

Table 7. Rate constants $(k)$, deactivation coefficients $(a)$, conversion capacities $\left(R_{0}\right)$, and overall selectivities to coke for the five catalysts.

\begin{tabular}{|c|c|c|c|c|c|c|c|c|}
\hline Sample & $\mathrm{t}_{0.5}(\mathrm{~h})$ & $\mathrm{t}_{0.8}(\mathrm{~h})$ & $\begin{array}{c}\mathrm{k}(\mathrm{mmol} \\
\mathrm{mol}_{\text {acid site }} \mathrm{-}^{-1} \mathrm{~h}^{-} \\
1 \text { ) }\end{array}$ & $\begin{array}{c}\mathrm{a}\left(\mathrm{g}_{\mathrm{cat}}\right. \\
\mathrm{mol}_{\left.\mathrm{MeOH}^{-1}\right)}\end{array}$ & $\begin{array}{c}\text { a (mol acid site } \\
\mathrm{mol}_{\left.\mathrm{MeOH}^{-1}\right)} \\
* 10^{-3}\end{array}$ & $\begin{array}{l}\mathrm{R}_{0}\left(\mathrm{~mol}_{\mathrm{MeOH}}\right. \\
\left.\mathrm{mol}_{\text {acidity }}{ }^{-1}\right)^{\text {a }}\end{array}$ & $\begin{array}{l}\mathrm{R}_{0}\left(\mathrm{~mol}_{\mathrm{MeOH}}\right. \\
\left.\text { mol }_{\text {acidity }}{ }^{-1}\right)^{\mathrm{b}}\end{array}$ & $\begin{array}{c}\text { Coke } \\
\text { selectivity } \\
\text { (C\%) }\end{array}$ \\
\hline Mordenite & 0.5 & 0.4 & 3.7 & 4.0 & 3.1 & 64 & 72 & 9.8 \\
\hline ZSM-22 & 1.4 & 1.1 & 1.1 & 1.3 & 0.5 & 491 & 514 & 1.0 \\
\hline ZSM-5 & 11 & 10 & 9.1 & 0.2 & 0.2 & 1415 & 1405 & 0.4 \\
\hline Beta & 6.5 & 3.4 & 2.2 & 0.3 & 0.3 & 898 & 1055 & 1.2 \\
\hline SAPO-34 & 13.3 & 10 & $5.5^{c}$ & 0.1 & 0.1 & 1136 & 1163 & 0.7 \\
\hline
\end{tabular}

\footnotetext{
a. Conversion capacity derived from Janssens' model [21].

b. Conversion capacity obtained by integration of the conversion curves.

c. For SAPO-34, no experimental measure of the density of Brønsted acid sites could be obtained, and the acid site density is estimated from the composition.
} 
The conversion capacities obtained by integration and from the model are very similar for all catalysts, despite the fact that the model initially was developed for ZSM-5. When comparing the activity of the catalysts according to the rate constant, k, ZSM-5 clearly surpasses the rest of catalysts. For a series of ZSM- 5 catalysts, it has been shown that this rate constant, when expressed in units per mass of catalyst, is linearly dependent on the density of acid sites [84]. This in turn means that a fixed rate constant would be observed when expressed in units per acid site. When comparing the rate constants in Table 7, it becomes evident that such a correlation does not exist when comparing different topologies. The most active catalyst (ZSM-5) is able to convert very nearly 10 times as many methanol molecules into hydrocarbons per hour as the least active catalyst (ZSM-22). Such topology dependent variations in activity, even when normalized to acidity, have also been observed previously [85] However, in this contribution, we are able to express the topology dependency of the rate constant (expressed per acid site) in a strictly quantitative manner. This consitutes a signficant improvement over previous contributions.

Mordenite displays the highest deactivation coefficient value followed by ZSM-22. As shown earlier, the lifetime of these two catalysts is much shorter than in ZSM-5, Beta and SAPO-34. For ZSM-5, it has been shown that the deactivation coefficient depends on the intensity ratio of the bands at 3726 and $3745 \mathrm{~cm}^{-1}$ in the FT-IR spectrum of the dehydrated catalysts [84]. This corresponds to the ratio between internal silanol defects and the external surface area of the catalyst crystals. We attempted to carry out the same analysis for the five catalysts of different topology studied here (FT-IR spectra are shown in Figures S.5-S.9 and the ratio is shown in Figure S.23), but no correlation could be found. This clearly demonstrates that the previously link between silanol defects and deactivation coefficient previously found for ZSM-5 catalysts cannot be extend across different catalyst topologies.

The factors influencing the deactivation coefficient can be further assessed by examining the overall selectivities to coke and the deactivation coefficients listed in Table 7. The overall selectivities to coke are estimated from the total coke from TGA relative to the conversion capacities, both values expressed in units of grams of carbon per gram catalyst. This results in a selectivity to coke in units of $\mathrm{C} \%$, conveniently expressing the percentage of methanol carbon atoms that end up as coke. For the rapidly deactivating Mordenite catalyst, the large deactivation coefficient is coupled with a remarkably high selectivity towards coke. However, for the other four materials, there is no correlation between the deactivation coefficient and the selectivity towards total coke. Clearly, the catalysts respond very differently when a certain amount of coke is deposited, again emphasizing the importance of topology. This analysis does not change if the deactivation coefficient is expressed in terms of acid site density rather than mass; see Table 7. Having exhausted the concentration of silanol defects, the acid site density, and the overall selectivity to coke as major parameters 
determining the magnitude of the deactivation coefficient, it becomes more probable that topology is the major feature that influences the deactivation behavior of the catalyst samples, and that this clearly overshadows the differences in physical characteristics (Table 1). However, we are not in a position to fully eliminate other, more subtle effects. Nevertheless, by carrying out careful catalyst characterization and a detailed kinetic analysis, normalizing per acid site, we are, in fact, able to rule out the three commonly encountered and plausible factors mentioned above that typically influence catalyst deactivation.

\subsection{Total coke - which parameter is decisive?}

It was found that the final, total amount of coke as determined by TGA for the completely deactivated catalysts varies greatly among the topologies (Tables 2-6). The analysis presented in Figures S.17 and S.18 reveals that the total coke correlates quite well with the BET surface area $\left(\mathrm{R}^{2}=\right.$ $0.88)$ and somewhat less well with the micropore volume $\left(R^{2}=0.78\right)$. Thus, it might be tempting to assume that deactivation occurs by pore filling and not poisoning of active sites by irreversible adsorbed coke species or external coking. However, we are not in a position to draw such a definitive conclusion about the coke formation and evolution mechanisms from the results obtained in this study. It is well established that e.g. fully deactivated ZSM-5 catalysts employed in the MTH reaction contain large aromatic deposits $(400+\mathrm{Da})$ that reside on the external surface of the zeolite crystals and block the pores [6, 18]. Interestingly, Hereijgers et al. [32], in the context of SAPO-34 discuss the possibility of an outer shell of external coke which traps small aromatics, volatile alkanes, and unreacted methanol and dimethyl ether within the micropores of the fully deactivated catalyst. Trapped volatile compounds have also been observed by Arstad and Kolboe [86]. It might be that such a scenario, which would be most likely for strongly diffusion limited topologies, can explain the correlation with the total weight loss during oxidation and the BET surface area. For the Beta catalyst, which is the only one in the present series that has an appreciable external surface area, the total amount of deposits appears to match the BET surface (which includes a contribution from the external surface) better than the micropore volume. Overall, these observations are reconcilable with the notion that for the totally deactivated samples, both the internal volume and the external surface are occupied by coke. 


\subsection{Qualitative assessments - UV-Raman spectroscopy}

To shed further light on chemical nature of the deactivating species, we have employed UV-Raman spectroscopy to study the deactivated catalyst samples.. This is a powerful tool in the qualitative analysis of carbonaceous species formed during the MTH process [87-89], and it is possible to discriminate among the several possible allotropic forms of carbon [90-92]. However, two major challenges exist. First, in order to avoid beam damage to the samples when utilizing the high power laser, sample movement (in this case rotation) is critical. Second, assignments are hampered by the lack of a comprehensive database of reference compounds. The use of high power UV laser excitation is crucial to increase the intensity of the signals of the coke compounds by resonance, and this study consitutes one of very few examples of the applicaton of this technique to investigate deactivated zeolite catalysts. The UV-Raman spectra of the completely deactivated catalysts as well as the corresponding chromatograms of the extracts obtained after the dissolution-extraction experiments are reported in Figure 6.

The reported assignments are based on literature [93-95], as well as the spectra of some reference compounds reported in Figure S.19.
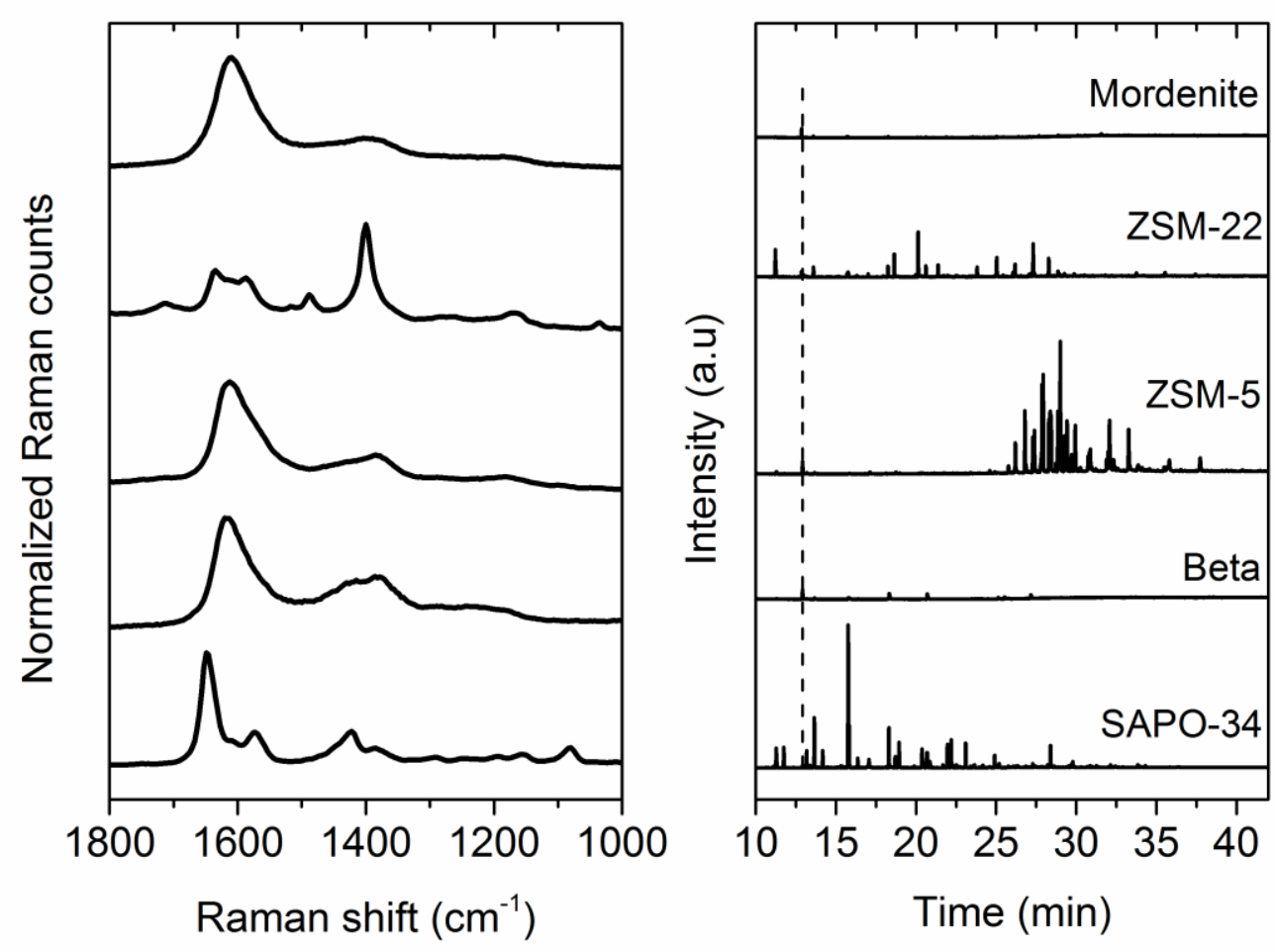

Figure 6. (Left) UV-Raman $(\lambda=244 \mathrm{~nm})$ spectra of completely deactivated samples. (Right) Chromatograms from the dissolution-extraction experiments for completely deactivated samples. All the peaks are normalized relative to the standard peak ortho-chloro-toluene indicated by the dashed line in the chromatograms. 
A first general observation for all the samples studied is that the Raman spectra of the coked samples are fully dominated by the bands assigned to the carbonaceous species, and that the zeolite framework bands, expected below $1200 \mathrm{~cm}^{-1}$, are absent. Figure S.20 (Supplementary Material) compares the spectra obtained for the coked ZSM- 5 with that of the fresh material.

From the UV-Raman experiments, we classify the materials into two main classes. The zeolites with 3D medium and large pores (Mordenite, Beta and ZSM-5) show relatively simple UV-Raman spectra dominated by the two major bands associated with extended carbon (see below), whereas the spectra obtained for the samples with more constrained 1D medium and small pores (ZSM-22 and SAPO-34) display much more fine structure, indicative of molecular species.

Even though the UV Raman spectra of the completely deactivated samples of Mordenite, Beta and ZSM-5 show generally broad and overlapping bands, they can be assigned to extended carbonaceous species for all catalysts [96]. However, it is difficult to unequivocally attribute the bands to a single kind of carbon. The most probable phase, according to the positions of $D$ and $G$ bands and their intensity ratio is an amorphous carbon (low $s p^{3}$ content, disordered graphitic domains), but also some $\mathrm{H}$ containing species can contribute. Even though the pores of Mordenite and zeolite Beta are quite large, they do not allow the build-up of such extended phases. It is therefore possible to state that for these two topologies, external coke predominates, in apparent agreement with the negligible amounts of soluble coke detected in the extracts.

Furthermore, for ZSM-5 (and to a smaller extent also Beta) more well defined peaks are superimposed on the carbon signals discussed so far. These are related to more well-defined, molecular coke species. For ZSM-5, these signals are in agreement with the presence of biphenyl (shoulder at $1585 \mathrm{~cm}^{-1}$ and small peaks at $1290 \mathrm{~cm}^{-1}$ and $1185 \mathrm{~cm}^{-1}$ ) and naphthalene and/or anthracene (possibly both contributing to the peak at $1390 \mathrm{~cm}^{-1}$ ). The spectrum obtained for zeolite Beta, shows a clear feature at $1380 \mathrm{~cm}^{-1}$, which could be signature of naphthalene derivatives (see reference spectra reported in Figure S.19). It should be emphasized that these assignments are not absolute, as other compounds for which reference spectra are not available, (e.g. structural isomers or compounds with similar functional groups but slightly different molecular weights) [97-99] might give rise to intensity in these ranges.

The situation is quite different for SAPO-34 and ZSM-22, which have small and medium sized pores and restricted transport properties. Sharp, molecule-like spectral features are observed in Figure 6, 
and the complexity of the spectra points to the coexistence of several species, as also observed in the extracts. It seems reasonable that internal coking, with large molecules unable to diffuse out of the catalysts leading to a blockage of the active sites in the micropores, plays a role for these two catalysts.

In the case of ZSM-22, the deactivation is related to polyaromatic species. Such compounds are seen both in the UV-Raman spectrum and they are detected in the dissolution-extraction experiments. The main signals are in agreement with the reference spectra of anthracene (main signal at $1400 \mathrm{~cm}^{-1}$, peak at $1630 \mathrm{~cm}^{-1}$ ), biphenyl (peaks at $1585 \mathrm{~cm}^{-1}$ and $1610 \mathrm{~cm}^{-1}$ ), fluorene (peaks at $1485 \mathrm{~cm}^{-1}$ and $1610 \mathrm{~cm}^{-1}$, the latter overlapping with one of biphenyl peak), and naphthalene $\left(1630 \mathrm{~cm}^{-1}\right.$, this peak is too intense to be related only to anthracene, and shoulder at $1380 \mathrm{~cm}^{-1}$ ). Furthermore, a pronounced band at $1710 \mathrm{~cm}^{-1}$ is probably ascribable to carbonyls. Notably, this feature is most pronounced for ZSM-22. However, oxygenated compounds are not readily identified in the extracts for this or any of the other catalysts. Clearly, this finding underscores the need for complementary analysis methods. Interestingly, Müller et al. [6] have verified the existence of oxygen containing coke in ZSM-5, in particular at the initial stages of deactivation, and shown how such compounds contribute to rapid deactivation.

The most distinct feature observed for SAPO-34 is the intense peak with maximum at $1650 \mathrm{~cm}^{-1}$. The high frequency of this signal is not compatible with that typical of condensed aromatics, and it is probably related to the presence of heavy olefins (see 1-hexene spectrum as general reference, Figure S.19). The presence of a small peak at $1290 \mathrm{~cm}^{-1}$ supports the existence of such compounds. This agrees well with the notion of trapped $\mathrm{C}_{4+}$ alkenes and alkanes residing in the pores of deactivated SAPO-34 discussed by Hereijgers et al [32]. Clearly, UV-Raman is one of few techniques that can be used to detect such volatile trapped species, again highlighting the importance of applying a variety of analysis methods

\subsection{Product shape selectivity vs catalyst deactivation}

In section 3.2, the product selectivities obtained for the five different catalysts are reported, whereas the content and structure of the deactivating species have been discussed in the preceding sections. It might be of some interest to evaluate to which extent these two catalyst properties are linked (if at all). Summarizing, based on the present and previous data cited in the results section, it can be stated that Mordenite yields a complex mixture of alkenes, alkanes, and aromatics, ranging from methane to hexamethylbenzene; ZSM-22 produces a nearly aromatics free product, rich in highly branched C5+ alkenes; ZSM-5 yields the typical MTG product, with a quite clear cut off at tetramethylbenzene (durene); Beta is characterized by a product spectrum dominated by light 
alkanes and penta- and hexamethylbenzene; whereas the MTO catalyst SAPO-34 yields mostly ethene and propene, with some linear C4 byproducts. It is generally accepted that the size of the heaviest product species formed over zeolite/zeotype catalysts, is governed by the size of the pore apertures [100]. In this work, the pore apertures increase in the following order: SAPO-34 < ZSM-22 < ZSM-5 < Mordenite < Beta [51] . With respect to the deactivating compounds, it is clear that ZSM-22 and SAPO-34 shows a large fraction of soluble coke species, that this fraction is substantially smaller for Mordenite and Beta, and that ZSM-5 shows an intermediate behavior. It might thus be argued that the low/negligible yield of aromatics seen in the gas phase effluent for ZSM-22 and SAPO-34 could be linked to the high fraction of such compounds seen in the soluble coke extracts when analyzed by GC-MS. Aromatic compounds are clearly formed also for these two catalysts, but they remain within the catalyst pores as trapped species. Interestingly, these compounds play very different roles in the two materials. In SAPO-34, the aromatic compounds act as key intermediates in product forming reactions [101]. For ZSM-22, on the other hand, they have been shown to be mostly inert towards incoming methanol and act primarily as deactivating species [73]. In a study relevant to the present, Bleken et al. [17] compared four different 3D zeolites with 10 membered ring pore apertures. The four materials gave very similar effluent product distribution. Even so, deactivation rates varied strongly between the materials, and it was concluded that the size of the channel intersections had a profound impact on the catalyst lifetime for otherwise comparable materials. Thus, it becomes clear that the deactivation by coking is strongly influenced by very subtle effects. 


\subsection{Structure-deactivation relationships}

- Mordenite $\bullet$ ZSM-22 $\Delta$ ZSM-5 $\boldsymbol{\nabla}$ Beta $\bullet$ SAPO-34

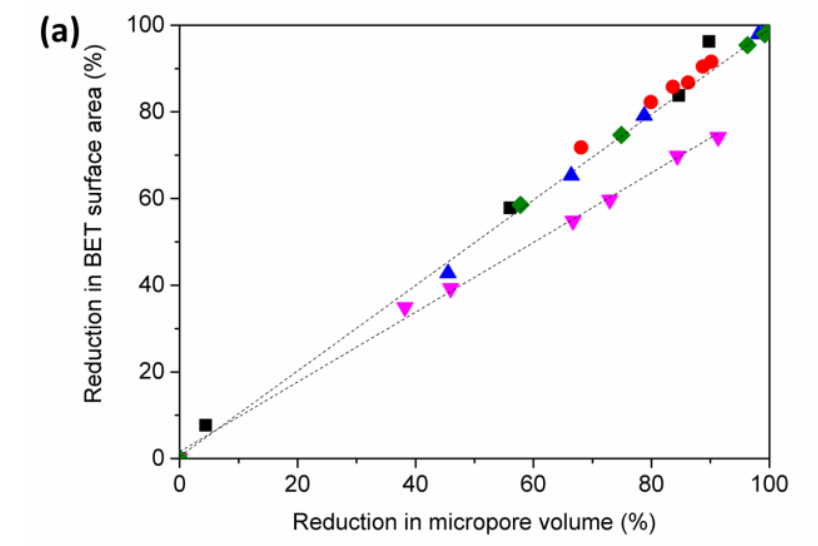

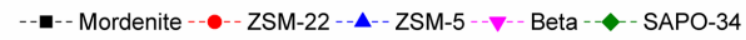
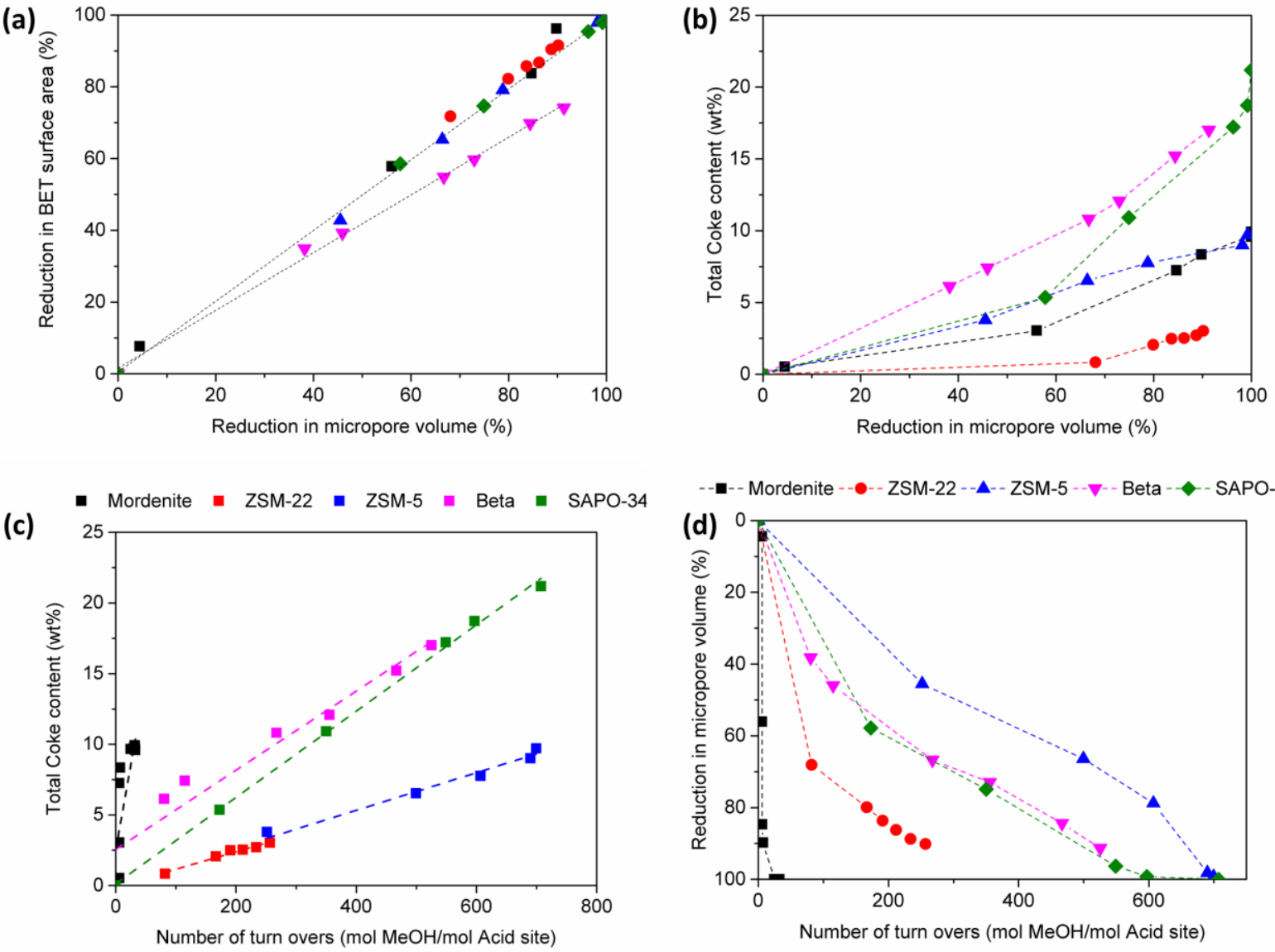

Figure 7. Structure-deactivation relationships for the five catalysts: (a) Reduction of BET surface area versus the reduction in micropore volume; (b) Total coke content from TGA versus reduction in micropore volume; (c) Total coke content from TGA versus number of turnovers of methanol; (d) Reduction in micropore volume versus number of turnovers. In panel a), the lines are obtained by regression with one separate regression analysis for zeolite Beta; the data for the other zeolites are fitted together. In panels (a) - (c), the data points are connected by straight lines.

A further, in depth analysis of the relationship between zeolite topology and catalyst deactivation can be reached by comparing how the various parameters presented in Tables 2-6 evolve among the five different catalysts. There are many ways to plot and analyze these measurements, and the four panels in Figure 7 have been selected as they highlight the most relevant features and also how the same underlying phenomenon can be manifested when evaluating seemingly different properties.

Panel (a) in Figure 7 shows the reduction of the BET surface area against the reduction in micropore volume. It may be noted that for ZSM-22 and zeolite Beta, there is not a total reduction of the micropore volume, even for the fully deactivated catalysts. Interestingly, for Mordenite, ZSM-22, ZSM-5, and SAPO-34, these values are very strongly correlated, and an excellent linear fit is achieved even when all four datasets are analyzed jointly. For zeolite Beta, the data follow a different line and parity. This is presumably a consequence of the significant external surface area of this sample. The 
fresh catalyst has an external surface area of $190 \mathrm{~m}^{2} / \mathrm{g}$ (Table 1), whereas the fully deactivated catalyst has a residual surface area of $175 \mathrm{~m}^{2} / \mathrm{g}$ (Table 5). This indeed confirms that the apparent similarity in the reduction in pore volume and cocomitant increase in coke content seen for the Beta zeolite is indeed an artefact of the remaining porisity. Indeed, it is safe to conclude that for all catalysts, the micropore volume and the BET surface area are reduced faster than the deposition of coke. Panel (a) shows that the BET surface area and micropore volume are strictly linearly dependent, a further analysis may be carried out according to either value without yielding different conclusions.

Panel (b) of Figure 7 displays the evolution of the total coke content from TGA against the reduction in the micropore volume. The curves are roughly stacked according to the total coke content, which is a manifestation and extension of the correlation between coke content and BET surface (which is linked to the micropore volume) previously presented for the fully deactivated materials in section 4.2. For all topologies, an upwards curvature is seen, meaning that the total coke content increases more slowly than the micropore volume/BET surface area is reduced with reaction time. This was already pointed out when presenting the data for the individual topologies (Tables 2-6).

Figure 7 (c) displays the accumulation of coke as a function of the amount of methanol converted into hydrocarbons per acid site. As advocated by Bhan and co-workers [102] such a parameter is more rigorous than time on stream when comparing data obtained at less than full conversion. The shapes of these curves warrant further discussion, keeping Haw's "burning cigar" model in mind. A strictly linear relationship between coke content and the number of turnovers suggests that coking occurs only in the zone of the catalyst bed where methanol is converted, that the selectivity to coke is constant, and that the actual rate of coke formation therefore depends on the degree of methanol conversion, in accordance to one of the assumptions made by Janssens [20]. A downwards curvature suggests that coke may be formed also from the products in the length of the reactor bed after the methanol conversion zone. The idea is then that as the active zone moves from inlet to outlet, the bed length available for coke formation from the products becomes smaller, and the overall coke formation is reduced. An upwards curvature would imply increased coke formation as the catalyst bed progressively becomes deactivated, which is hard to imagine. Although the number of data points is small and the uncertainties significant, we will attempt to categorize the data according to the two physically meaningful scenarios. For Mordenite and for the Beta zeolite, linear regression does not reasonably yield an intercept through the origin. Rather, a positive intercept is found, and the data appear to level off with increasing number of turnovers. For ZSM-22, ZSM-5 and SAPO-34, on the other hand, a linear fit through the origin does appear reasonable. Thus, the data indicate that coke formation from the products is relevant for Mordenite and zeolite Beta or perhaps for 12-rings in general. Whether the deactivating compounds are formed solely from methanol, as advocated by 
Schulz [7], or from a combination of methanol and products, or even by product-product condensation [14] consitutes a profound difference in the deactivation mechanism, which we identify as a key topic for further study. On the other hand, the data show that Janssens' model might be somewhat less suited for some topologies, which is not unreasonable, bearing in mind that it was developed originally for ZSM-5. A similar plot against reaction time would result in curves that slowly level off to reach an asymptotic value for the total coke content. The slopes vary widely among the topologies, and they cannot really be ranked according to total coke content, deactivation coefficient, or conversion capacities. This again emphasizes the fundamental difference in the deactivation behavior of these materials, as also discussed at the end of section 4.1.

The final panel of Figure 7 shows the reduction of micropore volume against the number of turnovers. This chart shows two differentiated regimes; the most pronounced decrease in micropore volume is seen initially, whereas at longer reaction times the reduction occurs more slowly and with a different slope. This is essentially the same behavior as discussed for panel (b).

For the large pore catalysts Mordenite and zeolite Beta, the fractions of soluble coke are always quite low. A clear maximum in both the fraction and the absolute amount of soluble coke is seen with increasing reaction time, as both these quantities become negligible for the completely deactivated materials, strongly indicating that external coking dominates. For ZSM-22 and ZSM-5, a slight increase in the fraction of soluble coke is seen with time on stream, whereas a slight decrease is observed for SAPO-34. However, given the significant uncertainties in these estimates, it could also be argued that for these three catalysts, the fraction of soluble coke is fairly constant with reaction time. The detection of soluble coke species even for the fully deactivated catalysts must be linked to the presence of molecular features in the UV-Raman spectra. The data highlighted in panels b) and d) of Figure 7 are more clear, where it is seen that the micropore volume and BET surface area decreases more profoundly than the corresponding increase in total coke content, and that this is a common feature which is observed for all the catalysts. These observations are reconcilable with a gradual process where coke initially is formed in the internal structure of the material (in line with the steep decrease in micropore volume and the maximum seen clearly for soluble coke in Mordenite and Beta) followed by a subsequent growth of extended, non-soluble coke compounds on the external surface of the zeolite particles $[15,103]$. Such discussions are often encountered in the literature, where also a migration and/or maturing of species from the internal voids to the external surface have been suggested [104-106]. However, we are cautious to embark on such discussions. Even though we see the transition from one type of coke species to another, none of the techniques employed here really allow us to discuss the actual physical migration of species (essentially carbon atoms) within a single zeolite crystallite as a function of reaction time. Moreover, it is very 
challenging to arrive at a definitive method to distinguish between "external" and "internal" coke. The dissolution extraction technique, although applied quantitatively here, has limitations as already discussed (see Supplementary Material). However, for ZSM-22 and SAPO-34, it is very probable that the majority of the compounds detected by GC-MS have resided in the internal volumes of these catalysts. Clearly, the molecular structure of the compounds reflect the topologies from which they are derived. Also, other work combining dissolution/extraction with detailed XRD analysis and theory, as outlined in section 3 , support this claim [76, 83]. For the other three topologies, the fraction and absolute amount of soluble coke species are always small, and their exact original location in/on the zeolite crystals become less interesting. The attempt to quantify "internal" coke based on the reduction of the micropore volumes presented in the Supplementary Material is certainly not valid for this dataset. The use of bulky solvents to dissolve external coke is discussed in the literature [107], but the actual origin of the compounds detected cannot be rigorously accounted for. Spectroscopic methods, such as the UV-Raman measurements presented here, are advantageous in the sense that they probe the entire range of coke compounds, from molecular to graphitic species. However, definitive assignments represent a challenge, and the possibility of quantifying the various signals is limited. Recently, LDI-TOF MS combined with coke extraction and dissolution-extraction has been used in a promising manner to analyze the "external" and total coke, respectively [6]. Given that this method relies on a dissolution/drying protocol for the analysis of the contributions of all coke compounds, volatile compounds (e.g. trapped isoalkanes) cannot be accounted for. Moreover, the method offers limited possibilities for exact structural identification, as the primary information obtained is the mass to charge ratio of the ions that reach the detector. 
Finally, it is of interest to compare the zeolites at the same level of coke deposition, that is to make a comparison that the same number of $C$ atoms deposited per acid site. Figure S.21 shows the conversion of methanol versus the total amount of carbon detected by TGA over the different zeolites. For completeness, Figure S.22 shows the conversion against the number of turnovers. Clearly, such a comparison cannot be achieved for a wide range of coke deposition, as the final, total amount of coke varies widely among the topologies. The data listed in Table 8 compare key characteristics of the catalysts at $5 \mathrm{C}$ atoms per acid site. The table was created from the total coke from TGA and the acid site density as measured with pyridine, except for SAPO-34, for which the site density was estimated from the elemental composition. Some of the data points were interpolated. Indicated is also the chromatogram of the soluble coke (see Supplementary Material) which closest corresponds to the same degree of coke deposition.

Table 8. Comparison of the TOS, conversion and textural properties over the 5 catalysts at the same level of carbon deposition per acid site.

\begin{tabular}{|c|c|c|c|c|c|c|c|}
\hline $\begin{array}{c}\text { Coke deposition } \\
\text { (mol C/mol Acid } \\
\text { site) } \\
\end{array}$ & Sample & TOS & $\begin{array}{l}\text { Conversion } \\
\text { (\%) }\end{array}$ & $\begin{array}{c}\text { Reduction in } \\
\text { micropore } \\
(\%)\end{array}$ & $\begin{array}{c}\text { BET } \\
\text { area } \\
\left(\mathrm{m}^{2} / \mathrm{g}\right) \\
\end{array}$ & $\begin{array}{c}\text { Total coke from } \\
\text { TGA (wt } \%)\end{array}$ & $\begin{array}{c}\text { Coke extract to } \\
\text { be compared }\end{array}$ \\
\hline 5 & Mordenite & $15^{\prime}$ & 100 & 85 & 81 & 7.2 & No. 2 \\
\hline 5 & ZSM-22 & $90^{\prime}$ & 41 & 86 & 31 & 2.6 & No. 4 \\
\hline 5 & ZSM-5 & $8 \mathrm{~h}$ & 100 & 66 & 144 & 6.5 & No. 2 \\
\hline 5 & Beta & $1 \mathrm{~h}$ & 99 & 38 & 442 & 6.1 & No. 1 \\
\hline 5 & SAPO-34 & $8 \mathrm{~h}$ & 91 & 75 & 179 & 10.9 & No. 2 \\
\hline
\end{tabular}

The total coke content from TGA differs among the samples, reflecting the differences in the acid site densities. The final, total coke deposition as mol of $\mathrm{C}$ per acid site for the fully deactivated can be read from the intercepts with the $x$-axis in Figure S.21. The values range from $6.2 \mathrm{C}$ atoms per acid site for ZSM-22 to 12.9 for the Beta zeolite. This conveys the same message as the final, total coke in weight percent from TGA (Tables 2-6), that the catalysts respond differently to different amounts of coke, or expressed alternatively, that they have differing coke tolerances. This is also why the remaining data in Table 8 vary strongly with topology when attempting to compare at the same level of coke deposition per acid site. 


\section{Conclusions}

In this work, we have examined the catalyst deactivation during the methanol to hydrocarbons reaction over five different commercial microporous catalysts (Mordenite, ZSM-22, ZSM-5, zeolite Beta, and SAPO-34) as a function of reaction time using nitrogen adsorption, thermogravimetric analysis, a dissolution-extraction protocol, and UV-Raman spectroscopy. The objective has been twofold: First, we have aimed to compare different evaluation methods for the determination of coke content; and second, we have sought to compare the differences in both activity and deactivation that can be ascribed to topology. By doing so, we arrive at fundamental new insights regarding the deactivation of zeolite catalysts by coking.

From the methodological perspective, this report describes one of few attempts to bring the commonly employed dissolution-extraction protocol on a quantitative foundation. It is found that dissolution of spent catalysts followed by extraction and GC-MS analysis affords detection of only a fraction of the total coke content (as determined by TGA). Moreover, the magnitude of this fraction varies strongly among the topologies. The maximum value of this fraction is about $5 \%$ for zeolite Beta and $52 \%$ for SAPO-34.

An attempt to estimate the concentration of "internal" coke from the reduction in pore volume from N2 adsorption yielded unreasonable results.

We successfully demonstrate that UV-Raman spectroscopy provides a non-destructive method to attain the fingerprint of all the hydrocarbon compounds deposited on the spent catalysts. Sample spinning is required to avoid sample damage by the high power UV-laser, which was applied to avoid fluorescence and obtain resonance conditions. It is possible to distinguish between molecular and graphitic coke compounds, but provided the availability of reference spectra; it is possible to distinguish also between single species or single functional groups. The appearance of distinct, molecule like features in the Raman spectra is linked to a high concentration of soluble coke species. This method also allows the detection of trapped volatile species not otherwise easily detected, seen in particular for SAPO-34.

The catalyst characterization and the kinetic evaluation of the catalyst performance data provide a quantitative basis for comparison of the five catalysts. The rate constants for the conversion of methanol to hydrocarbons differ by a factor close to 10 among the topologies when expressed per acid site. ZSM-5 is the most active catalyst, ZSM-22 the least. Further, the rate of deactivation (expressed as the loss of active sites per methanol molecule converted per time) cannot be 
correlated with the concentration of internal silanol defects (in contrast to previous observations for a series of ZSM-5 catalysts), the acid site density, the overall coke selectivity, or the final total coke content. Together, this indicates that the major differences seen among the catalyst can be ascribed primarily to topology rather than other catalyst characteristics.

Turning finally to the deactivation behavior, it is observed that the final, total amount of coke as detected by TGA for the completely deactivated catalysts varies strongly among the topologies. SAPO-34 requires 7 times more coke that ZSM-22 to be fully deactivated. The total coke content is well correlated to the BET surface area measured for the fresh catalysts across the series, and more so than to the micropore volume. This indicates that for the totally deactivated samples, both the internal volume and the external surface are occupied by coke.

By plotting the evolution of total coke from TGA against the number of catalytic turnovers, a distinct difference between the 8- and 10-ring catalysts (SAPO-34, ZSM-22, ZSM-5) and the 12-ring catalysts (Mordenite and Beta) is seen. For the first group of catalysts, a linear evolution in total coke is seen, starting from the origin. In contrast, a leveling off with the number of turnovers is seen for the 12rings. This indicates a profound difference in the coking mechanism. For the 8- and 10-rings, it can be assumed that the presence of methanol is required for coke formation, whereas for the 12-rings, product condensation also constitutes a mechanism for coke formation. We identify this as a key point for further studies.

For all materials it is observed that the BET surface area and the micropore volume (which are very strongly correlated) decrease substantially faster than the content of total coke increases with reaction time. This demonstrates that the reaction/deactivation in all catalysts begins with a reduction of the access to the micropores, in line with previous reports.

Concerning both the fraction of coke compounds detected by the dissolution-extraction method relative to the total coke from TGA as well as the absolute amount of soluble compounds, it appears that for Mordenite and Beta, a small maximum is seen at short reaction times, before the amount of soluble compounds essentially goes to zero. For ZSM-22, ZSM-5, and SAPO-34, the fraction of soluble compounds remains appreciable with reaction time. Consequently, there is an accumulation of soluble compounds as the total coke content increases. There is a clear link between the detection of soluble compounds and the UV-Raman spectra: For fully deactivated Mordenite and zeolite Beta, virtually no soluble compounds are detected, and the UV-Raman spectra are basically the signature of extended carbonaceous (graphitic) species. For ZSM-22 and SAPO-34, on the other hand, a large fraction of soluble compounds are found, and the UV-Raman spectra correspondingly show distinct molecular features of relatively high intensity. For the particular ZSM-5 sample employed here, an 
intermediate behavior is seen. By evaluating the product selectivities, it appears that for the catalysts with limited mass transport properties (ZSM-22 and SAPO-34); even the smallest aromatic compounds remain trapped within the pore systems, giving rise to a significant fraction of molecular coke.

To summarize, it is clear that the soluble coke detected in the extracts and seen using UV-Raman for SAPO-34 and ZSM-22 can be considered to be largely internal coke, as the molecular structures of the coke compounds reflect the pore systems of the materials. This is also in agreement with previous studies relying on XRD and theoretical simulations. For Mordenite and zeolite Beta and to some extent ZSM-5, the formation of coke compounds which are too large to reasonably be characterized as molecules or internal coke, appears to dominate. These materials show relatively simple UV-Raman spectra dominated by the two major bands associated with extended carbon phases or external coke.

\section{Acknowledgements}

This publication is part of the European Industrial Doctorate Project "ZeoMorph" (Grant Agreement No. 606965). The financial support from the European Research Council via Marie Curie Actions (FP7PEOPLE-2013-ITN-EID) is acknowledged. Dr. Anna M. Lind and Dr. Bjørnar Arstad at SINTEF Materials and Chemistry are kindly acknowledged for preparing the SAPO-34 catalyst. 


\section{References}

[1] M. Stöcker, Methanol-to-hydrocarbons: catalytic materials and their behavior, Microporous and Mesoporous Materials, 29 (1999) 3-48.

[2] F.J. Keil, Methanol-to-hydrocarbons: Process technology, Microporous and Mesoporous Materials, 29 (1999) 49-66.

[3] U. Olsbye, S. Svelle, M. Bjørgen, P. Beato, T.V.W. Janssens, F. Joensen, S. Bordiga, K.P. Lillerud, Conversion of Methanol to Hydrocarbons: How Zeolite Cavity and Pore Size Controls Product Selectivity, Angewandte Chemie International Edition, 51 (2012) 5810-5831.

[4] P. Tian, Y. Wei, M. Ye, Z. Liu, Methanol to olefins (MTO): From fundamentals to commercialization, ACS Catalysis, 5 (2015) 1922-1938.

[5] S. Teketel, W. Skistad, S. Benard, U. Olsbye, K.P. Lillerud, P. Beato, S. Svelle, Shape Selectivity in the Conversion of Methanol to Hydrocarbons: The Catalytic Performance of One-Dimensional 10Ring Zeolites: ZSM-22, ZSM-23, ZSM-48, and EU-1, ACS Catalysis, 2 (2012) 26-37.

[6] S. Müller, Y. Liu, M. Vishnuvarthan, X. Sun, A.C. van Veen, G.L. Haller, M. Sanchez-Sanchez, J.A. Lercher, Coke formation and deactivation pathways on H-ZSM-5 in the conversion of methanol to olefins, Journal of Catalysis, 325 (2015) 48-59.

[7] H. Schulz, "Coking" of zeolites during methanol conversion: Basic reactions of the MTO-, MTP- and MTG processes, Catalysis Today, 154 (2010) 183-194.

[8] M. Guisnet, P. Magnoux, Fundamental description of deactivation and regeneration of acid zeolites, in: B. Delmon, G.F. Froment (Eds.) Studies in Surface Science and Catalysis, Elsevier, 1994, pp. 53-68.

[9] J.A. Moulijn, A.E. van Diepen, F. Kapteijn, Catalyst deactivation: is it predictable?: What to do?, Applied Catalysis A: General, 212 (2001) 3-16.

[10] J. Kim, M. Choi, R. Ryoo, Effect of mesoporosity against the deactivation of MFI zeolite catalyst during the methanol-to-hydrocarbon conversion process, Journal of Catalysis, 269 (2010) 219-228.

[11] H. Schulz, K. Lau, M. Claeys, Kinetic regimes of zeolite deactivation and reanimation, Applied Catalysis A: General, 132 (1995) 29-40.

[12] K. Barbera, S. Sorensen, S. Bordiga, J. Skibsted, H. Fordsmand, P. Beato, T.V.W. Janssens, Role of internal coke for deactivation of ZSM-5 catalysts after low temperature removal of coke with NO 2 , Catalysis Science and Technology, 2 (2012) 1196-1206.

[13] F. Schmidt, C. Hoffmann, F. Giordanino, S. Bordiga, P. Simon, W. Carrillo-Cabrera, S. Kaskel, Coke location in microporous and hierarchical ZSM-5 and the impact on the MTH reaction, Journal of Catalysis, 307 (2013) 238-245.

[14] U. Olsbye, S. Svelle, K.P. Lillerud, Z.H. Wei, Y.Y. Chen, J.F. Li, J.G. Wang, W.B. Fan, The formation and degradation of active species during methanol conversion over protonated zeotype catalysts, Chemical Society Reviews, 44 (2015) 7155-7176.

[15] B. Liu, D. Slocombe, M. AlKinany, H. AlMegren, J. Wang, J. Arden, A. Vai, S. Gonzalez-Cortes, T. Xiao, V. Kuznetsov, P.P. Edwards, Advances in the study of coke formation over zeolite catalysts in the methanol-to-hydrocarbon process, Applied Petrochemical Research, (2016) 1-7.

[16] M. Bjørgen, S. Akyalcin, U. Olsbye, S. Benard, S. Kolboe, S. Svelle, Methanol to hydrocarbons over large cavity zeolites: Toward a unified description of catalyst deactivation and the reaction mechanism, Journal of Catalysis, 275 (2010) 170-180.

[17] F. Bleken, W. Skistad, K. Barbera, M. Kustova, S. Bordiga, P. Beato, K.P. Lillerud, S. Svelle, U. Olsbye, Conversion of methanol over 10-ring zeolites with differing volumes at channel intersections: comparison of TNU-9, IM-5, ZSM-11 and ZSM-5, Physical Chemistry Chemical Physics, 13 (2011) 2539-2549.

[18] M. Bjørgen, S. Svelle, F. Joensen, J. Nerlov, S. Kolboe, F. Bonino, L. Palumbo, S. Bordiga, U. Olsbye, Conversion of methanol to hydrocarbons over zeolite H-ZSM-5: On the origin of the olefinic species, Journal of Catalysis, 249 (2007) 195-207. 
[19] J.W. Park, J.Y. Lee, K.S. Kim, S.B. Hong, G. Seo, Effects of cage shape and size of 8-membered ring molecular sieves on their deactivation in methanol-to-olefin (MTO) reactions, Applied Catalysis A: General, 339 (2008) 36-44.

[20] T.V.W. Janssens, A new approach to the modeling of deactivation in the conversion of methanol on zeolite catalysts, Journal of Catalysis, 264 (2009) 130-137.

[21] T.V.W. Janssens, S. Svelle, U. Olsbye, Kinetic modeling of deactivation profiles in the methanolto-hydrocarbons (MTH) reaction: A combined autocatalytic-hydrocarbon pool approach, Journal of Catalysis, 308 (2013) 122-130.

[22] G. Sastre, Confinement effects in methanol to olefins catalysed by zeolites: A computational review, Frontiers of Chemical Science and Engineering, 10 (2016) 76-89.

[23] F.L. Bleken, K. Barbera, F. Bonino, U. Olsbye, K.P. Lillerud, S. Bordiga, P. Beato, T.V.W. Janssens, S. Svelle, Catalyst deactivation by coke formation in microporous and desilicated zeolite H-ZSM-5 during the conversion of methanol to hydrocarbons, Journal of Catalysis, 307 (2013) 62-73.

[24] I. Yarulina, J. Goetze, C. Gucuyener, L. van Thiel, A. Dikhtiarenko, J. Ruiz-Martinez, B.M. Weckhuysen, J. Gascon, F. Kapteijn, Methanol-to-olefins process over zeolite catalysts with DDR topology: effect of composition and structural defects on catalytic performance, Catalysis Science \& Technology, 6 (2016) 2663-2678.

[25] J. Chen, J. Li, Y. Wei, C. Yuan, B. Li, S. Xu, Y. Zhou, J. Wang, M. Zhang, Z. Liu, Spatial confinement effects of cage-type SAPO molecular sieves on product distribution and coke formation in methanolto-olefin reaction, Catalysis Communications, 46 (2014) 36-40.

[26] J. Li, Y. Wei, J. Chen, S. Xu, P. Tian, X. Yang, B. Li, J. Wang, Z. Liu, Cavity Controls the Selectivity: Insights of Confinement Effects on MTO Reaction, ACS Catalysis, 5 (2015) 661-665.

[27] Y. Bhawe, M. Moliner-Marin, J.D. Lunn, Y. Liu, A. Malek, M. Davis, Effect of Cage Size on the Selective Conversion of Methanol to Light Olefins, ACS Catalysis, 2 (2012) 2490-2495.

[28] M.A. Deimund, J.E. Schmidt, M.E. Davis, Effect of Pore and Cage Size on the Formation of Aromatic Intermediates During the Methanol-to-Olefins Reaction, Top Catal, 58 (2015) 416-423.

[29] J.W. Park, G. Seo, IR study on methanol-to-olefin reaction over zeolites with different pore structures and acidities, Applied Catalysis A: General, 356 (2009) 180-188.

[30] N.H. Ahn, S. Seo, S.B. Hong, Small-pore molecular sieves SAPO-57 and SAPO-59: synthesis, characterization, and catalytic properties in methanol-to-olefins conversion, Catalysis Science \& Technology, 6 (2016) 2725-2734.

[31] S. Teketel, S. Svelle, K.-P. Lillerud, U. Olsbye, Shape-Selective Conversion of Methanol to Hydrocarbons Over 10-Ring Unidirectional-Channel Acidic H-ZSM-22, ChemCatChem, 1 (2009) 78-81.

[32] B.P.C. Hereijgers, F. Bleken, M.H. Nilsen, S. Svelle, K.-P. Lillerud, M. Bjørgen, B.M. Weckhuysen, U. Olsbye, Product shape selectivity dominates the Methanol-to-Olefins (MTO) reaction over H-SAPO-34 catalysts, Journal of Catalysis, 264 (2009) 77-87.

[33] M. Guisnet, P. Magnoux, Coking and deactivation of zeolites: Influence of the Pore Structure, Applied Catalysis, 54 (1989) 1-27.

[34] J.F. Haw, D.M. Marcus, Well-defined (supra)molecular structures in zeolite methanol-to-olefin catalysis, Top Catal, 34 41-48.

[35] D.S. Wragg, M.G. O'Brien, F.L. Bleken, M. Di Michiel, U. Olsbye, H. Fjellvåg, Watching the Methanol - to - Olefin Process with Time - and Space - Resolved High - Energy Operando X - ray Diffraction, Angewandte Chemie International Edition, 51 (2012) 7956-7959.

[36] D.S. Wragg, R.E. Johnsen, M. Balasundaram, P. Norby, H. Fjellvåg, A. Grønvold, T. Fuglerud, J. Hafizovic, $\varnothing$.B. Vistad, D. Akporiaye, SAPO-34 methanol-to-olefin catalysts under working conditions: A combined in situ powder X-ray diffraction, mass spectrometry and Raman study, Journal of Catalysis, 268 (2009) 290-296.

[37] S. Muller, Y. Liu, F.M. Kirchberger, M. Tonigold, M. Sanchez-Sanchez, J.A. Lercher, Hydrogen Transfer Pathways during Zeolite Catalyzed Methanol Conversion to Hydrocarbons, J Am Chem Soc, 138 (2016) 15994-16003.

[38] M.M. Mertens, in: W. Patent (Ed.), February 6, 2009.

[39] B. Hinrichsen, R.E. Dinnebier, M. Jansen, Powder Diffraction: Theory and Practice, (2008). 
[40] A. Le Bail, Whole powder pattern decomposition methods and applications: a retrospection, Powder Diffraction, 20 (2005) 316-326.

[41] J. Rouquerol, P. Llewellyn, F. Rouquerol, Is the bet equation applicable to microporous adsorbents?, in: F.R.-R.J.R. P.L. Llewellyn, N. Seaton (Eds.) Studies in Surface Science and Catalysis, Elsevier, 2007, pp. 49-56.

[42] S. Lowell, J.E. Shields, M.A. Thomas, M. Thommes, Micropore Analysis, in: Characterization of Porous Solids and Powders: Surface Area, Pore Size and Density, Springer Netherlands, Dordrecht, 2004, pp. 129-156.

[43] E. Selli, L. Forni, Comparison between the surface acidity of solid catalysts determined by TPD and FTIR analysis of pre-adsorbed pyridine, Microporous and Mesoporous Materials, 31 (1999) 129140.

[44] T. Yamamoto, T. Tanaka, T. Matsuyama, T. Funabiki, S. Yoshida, Alumina-supported rare-earth oxides characterized by acid-catalyzed reactions and spectroscopic methods, The Journal of Physical Chemistry B, 105 (2001) 1908-1916.

[45] L. Kustov, V. Kazanskii, S. Beran, L. Kubelkova, P. Jiru, Adsorption of carbon monoxide on ZSM-5 zeolites: infrared spectroscopic study and quantum-chemical calculations, Journal of Physical Chemistry, 91 (1987) 5247-5251.

[46] T.K. Phung, G. Busca, On the Lewis acidity of protonic zeolites, Applied Catalysis A: General, 504 (2015) 151-157.

[47] J.A. Lercher, A. Jentys, Chapter 13 Infrared and raman spectroscopy for characterizing zeolites, in: H.v.B.A.C. Jiří Čejka, S. Ferdi (Eds.) Studies in Surface Science and Catalysis, Elsevier, 2007, pp. 435476.

[48] D.M. Bibby, C.G. Pope, Sorption studies of coke deposited on ZSM-5, Journal of Catalysis, 116 (1989) 407-414.

[49] P. Magnoux, P. Roger, C. Canaff, V. Fouche, N.S. Gnep, M. Guisnet, New technique for the characterization of carbonaceous compounds responsible for zeolite deactivation, Stud. Surf. Sci. Catal., 34 (1987) 317-330.

[50] A. Damin, M. Signorile, F. Bonino, S. Bordiga, R. Disa, submitted, n. 102015000069819, in, Italy, 2015.

[51] C. Baerlocher, L.B. McCusker, D.H. Olson, Atlas of Zeolite Framework Types, 7th ed., Elsevier, Amsterdam, 2007.

[52] J.W. Park, S.J. Kim, M. Seo, S.Y. Kim, Y. Sugi, G. Seo, Product selectivity and catalytic deactivation of MOR zeolites with different acid site densities in methanol-to-olefin (MTO) reactions, Applied Catalysis A: General, 349 (2008) 76-85.

[53] L.-T. Yuen, S.I. Zones, T.V. Harris, E.J. Gallegos, A. Auroux, Product selectivity in methanol to hydrocarbon conversion for isostructural compositions of AFI and CHA molecular sieves, Microporous Materials, 2 (1994) 105-117.

[54] F. Bleken, M. Bjørgen, L. Palumbo, S. Bordiga, S. Svelle, K.-P. Lillerud, U. Olsbye, The Effect of Acid Strength on the Conversion of Methanol to Olefins Over Acidic Microporous Catalysts with the CHA Topology, Top Catal, 52 (2009) 218-228.

[55] I.M. Dahl, H. Mostad, D. Akporiaye, R. Wendelbo, Structural and chemical influences on the MTO reaction: a comparison of chabazite and SAPO-34 as MTO catalysts, Microporous and Mesoporous Materials, 29 (1999) 185-190.

[56] Q. Zhu, J.N. Kondo, R. Ohnuma, Y. Kubota, M. Yamaguchi, T. Tatsumi, The study of methanol-toolefin over proton type aluminosilicate CHA zeolites, Microporous and Mesoporous Materials, 112 (2008) 153-161.

[57] D. Mores, J. Kornatowski, U. Olsbye, B.M. Weckhuysen, Coke Formation during the Methanolto-Olefin Conversion: In Situ Microspectroscopy on Individual H-ZSM-5 Crystals with Different Brønsted Acidity, Chemistry - A European Journal, 17 (2011) 2874-2884.

[58] M. Guisnet, L. Costa, F.R. Ribeiro, Prevention of zeolite deactivation by coking, Journal of Molecular Catalysis A: Chemical, 305 (2009) 69-83. 
[59] K. Chakarova, K. Hadjiivanov, H-bonding of zeolite hydroxyls with weak bases: FTIR study of CO and N 2 adsorption on H-D-ZSM-5, Journal of Physical Chemistry C, 115 (2011) 4806-4817.

[60] S. Kotrel, J.H. Lunsford, H. Knözinger, Characterizing zeolite acidity by spectroscopic and catalytic means: A comparison, Journal of Physical Chemistry B, 105 (2001) 3917-3921.

[61] A. Zecchina, G. Spoto, S. Bordiga, Probing the acid sites in confined spaces of microporous materials by vibrational spectroscopy, Physical Chemistry Chemical Physics, 7 (2005) 1627-1642.

[62] S. Bordiga, L. Regli, D. Cocina, C. Lamberti, M. Bjørgen, K.P. Lillerud, Assessing the acidity of high silica chabazite H-SSZ-13 by FTIR using $\mathrm{CO}$ as molecular probe: Comparison with H-SAPO-34, Journal of Physical Chemistry B, 109 (2005) 2779-2784.

[63] J. Sauer, K.P. Schröder, V. Termath, Comparing the acidities of microporous aluminosilicate and silico-aluminophosphate catalysts: A combined quantum mechanics-interatomic potential function study, Collection of Czechoslovak Chemical Communications, 63 (1998) 1394-1408.

[64] J. Haw, D. Marcus, Well-defined (supra)molecular structures in zeolite methanol-to-olefin catalysis, Top Catal, 34 (2005) 41-48.

[65] M. Luo, H. Zang, B. Hu, B. Wang, G. Mao, Evolution of confined species and their effects on catalyst deactivation and olefin selectivity in SAPO-34 catalyzed MTO process, RSC Advances, 6 (2016) 17651-17658.

[66] D. Rojo-Gama, S. Etemadi, E. Kirby, K.P. Lillerud, P. Beato, S. Svelle, U. Olsbye, Time- and spaceresolved study of the Methanol to Hydrocarbons (MTH) reaction - influence of zeolite topology on deactivation patterns, Faraday Discuss., (2016).

[67] P. del Campo, W.A. Slawinski, R. Henry, M.W. Erichsen, S. Svelle, P. Beato, D. Wragg, U. Olsbye, Time- and space-resolved high energy operando X-ray diffraction for monitoring the methanol to hydrocarbon reaction over H-ZSM-22 zeolite catalyst in different conditions, Surface Science.

[68] P. Dejaifve, A. Auroux, P.C. Gravelle, J.C. Védrine, Z. Gabelica, E.G. Derouane, Methanol conversion on acidic ZSM-5, offretite, and mordenite zeolites: A comparative study of the formation and stability of coke deposits, Journal of Catalysis, 70 (1981) 123-136.

[69] Y. Liu, S. Müller, D. Berger, J. Jelic, K. Reuter, M. Tonigold, M. Sanchez-Sanchez, J.A. Lercher, Formation Mechanism of the First Carbon-Carbon Bond and the First Olefin in the Methanol Conversion into Hydrocarbons, Angewandte Chemie, 128 (2016) 5817-5820.

[70] G.J. Hutchings, F. Gottschalk, R. Hunter, Comments on "kinetic model for methanol conversion to olefins" with respect to methane formation at low conversion, Industrial \& Engineering Chemistry Research, 26 (1987) 635-637.

[71] J.M. Fougerit, N.S. Gnep, M. Guisnet, Selective transformation of methanol into light olefins over a mordenite catalyst: reaction scheme and mechanism, Microporous and Mesoporous Materials, 29 (1999) 79-89.

[72] S. Teketel, U. Olsbye, K.P. Lillerud, P. Beato, S. Svelle, Co-conversion of methanol and light alkenes over acidic zeolite catalyst H-ZSM-22: Simulated recycle of non-gasoline range products, Applied Catalysis A: General, 494 (2015) 68-76.

[73] S. Teketel, U. Olsbye, K.-P. Lillerud, P. Beato, S. Svelle, Selectivity control through fundamental mechanistic insight in the conversion of methanol to hydrocarbons over zeolites, Microporous and Mesoporous Materials, 136 (2010) 33-41.

[74] J.B. Wang, Y.X. Wei, J.Z. Li, S.T. Xu, W.N. Zhang, Y.L. He, J.R. Chen, M.Z. Zhang, A.M. Zheng, F. Deng, X.W. Guo, Z.M. Liu, Direct observation of methylcyclopentenyl cations (MCP+) and olefin generation in methanol conversion over TON zeolite, Catalysis Science \& Technology, 6 (2016) 89-97.

[75] S. Svelle, F. Joensen, J. Nerlov, U. Olsbye, K.P. Lillerud, S. Kolboe, M. Bjørgen, Conversion of methanol into hydrocarbons over zeolite H-ZSM-5: Ethene formation is mechanistically separated from the formation of higher alkenes, Journal of the American Chemical Society, 128 (2006) 1477014771.

[76] S. Teketel, S. Svelle, K.P. Lillerud, U. Olsbye, Shape - Selective Conversion of Methanol to Hydrocarbons Over 10 - Ring Unidirectional - Channel Acidic H - ZSM - 22, ChemCatChem, 1 (2009) 78-81. 
[77] F.L. Bleken, T.V.W. Janssens, S. Svelle, U. Olsbye, Product yield in methanol conversion over ZSM-5 is predominantly independent of coke content, Microporous and Mesoporous Materials, 164 (2012) 190-198.

[78] S. Svelle, L. Sommer, K. Barbera, P.N.R. Vennestrøm, U. Olsbye, K.P. Lillerud, S. Bordiga, Y.-H. Pan, P. Beato, How defects and crystal morphology control the effects of desilication, Catalysis Today, 168 (2011) 38-47.

[79] G. McLellan, R. Howe, L. Parker, D. Bibby, Effects of coke formation on the acidity of ZSM-5, Journal of Catalysis, 99 (1986) 486-491.

[80] D.M. Bibby, G.D. McLellan, R.F. Howe, Effects of Coke Formation and Removal on the Acidity Of ZSM-5, in: B. Delmon, G.F. Froment (Eds.) Studies in Surface Science and Catalysis, Elsevier, 1987, pp. 651-658.

[81] M. Bjørgen, F. Joensen, K.-P. Lillerud, U. Olsbye, S. Svelle, The mechanisms of ethene and propene formation from methanol over high silica H-ZSM-5 and H-beta, Catalysis Today, 142 (2009) 90-97.

[82] R.L. Smith, S. Svelle, P. del Campo, T. Fuglerud, B. Arstad, A. Lind, S. Chavan, M.P. Attfield, D. Akporiaye, M.W. Anderson, CHA/AEl intergrowth materials as catalysts for the Methanol-to-Olefins process, Applied Catalysis A: General, 505 (2015) 1-7.

[83] M. Zokaie, D.S. Wragg, A. Grønvold, T. Fuglerud, J.H. Cavka, K.P. Lillerud, O. Swang, Unit cell expansion upon coke formation in a SAPO-34 catalyst: A combined experimental and computational study, Microporous and Mesoporous Materials, 165 (2013) 1-5.

[84] K. Barbera, F. Bonino, S. Bordiga, T.V.W. Janssens, P. Beato, Structure-deactivation relationship for ZSM-5 catalysts governed by framework defects, Journal of Catalysis, 280 (2011) 196-205.

[85] S. Svelle, U. Olsbye, F. Joensen, M. Bjørgen, Conversion of Methanol to Alkenes over Mediumand Large-Pore Acidic Zeolites: Steric Manipulation of the Reaction Intermediates Governs the Ethene/Propene Product Selectivity, The Journal of Physical Chemistry C, 111 (2007) 17981-17984.

[86] B. Arstad, S. Kolboe, Methanol-to-hydrocarbons reaction over SAPO-34. Molecules confined in the catalyst cavities at short time on stream, Catal Lett, 71 (2001) 209-212.

[87] C. Li, P.C. Stair, Ultraviolet Raman spectroscopy characterization of coke formation in zeolites, Catal. Today, 33 (1997) 353-360.

[88] Y.T. Chua, P.C. Stair, An ultraviolet Raman spectroscopic study of coke formation in methanol to hydrocarbons conversion over zeolite H-MFI, J. Catal., 213 (2003) 39-46.

[89] P. Beato, E. Schachtl, K. Barbera, F. Bonino, S. Bordiga, Operando Raman spectroscopy applying novel fluidized bed micro-reactor technology, Catal. Today, 205 (2013) 128-133.

[90] A.C. Ferrari, J. Robertson, Interpretation of Raman spectra of disordered and amorphous carbon, Phys. Rev. B, 61 (2000) 14095-14107.

[91] M.S. Dresselhaus, G. Dresselhaus, R. Saito, A. Jorio, Raman spectroscopy of carbon nanotubes, Physics Reports-Review Section of Physics Letters, 409 (2005) 47-99.

[92] A.C. Ferrari, J.C. Meyer, V. Scardaci, C. Casiraghi, M. Lazzeri, F. Mauri, S. Piscanec, D. Jiang, K.S. Novoselov, S. Roth, A.K. Geim, Raman spectrum of graphene and graphene layers, Physical Review Letters, 97 (2006) 187401.

[93] S.A. Asher, C.R. Johnson, Raman Spectroscopy of a Coal Liquid Shows That Fluorescence Interference Is Minimized with Ultraviolet Excitation, Science, 225 (1984) 311-313.

[94] J.P. Peng, D.L. Cedeno, C. Manzanares, Cis- and trans-3-hexene: infrared spectrum in liquid argon solution, ab initio calculations of equilibrium geometry, normal coordinate analysis, and vibrational assignments, J. Mol. Struct., 440 (1998) 265-288.

[95] M. Signorile, F. Bonino, A. Damin, S. Bordiga, In Situ Resonant UV-Raman Spectroscopy of Polycyclic Aromatic Hydrocarbons, J. Phys. Chem. C, 119 (2015) 11694-11698.

[96] A.C. Ferrari, J. Robertson, Resonant Raman spectroscopy of disordered, amorphous, and diamondlike carbon, Phys. Rev. B, 64 (2001) 075414.

[97] A. Alparone, V. Librando, Raman DFT study of dimethylnaphthalenes: isomer identification and prediction of biodegradation rate coefficients, Structural Chemistry, 23 (2012) 1467-1474. 
[98] T. Prabhu, S. Periandy, S. Mohan, Spectroscopic (FTIR and FT Raman) analysis and vibrational study on 2,3-dimethyl naphthalene using ab-initio HF and DFT calculations, Spectrochimica Acta Part A: Molecular and Biomolecular Spectroscopy, 78 (2011) 566-574.

[99] M. Tommasini, C. Castiglioni, G. Zerbi, Raman scattering of molecular graphenes, Physical Chemistry Chemical Physics, 11 (2009) 10185-10194.

[100] S. Teketel, L.F. Lundegaard, W. Skistad, S.M. Chavan, U. Olsbye, K.P. Lillerud, P. Beato, S. Svelle, Morphology-induced shape selectivity in zeolite catalysis, Journal of Catalysis, 327 (2015) 22-32.

[101] B. Arstad, S. Kolboe, The Reactivity of Molecules Trapped within the SAPO-34 Cavities in the Methanol-to-Hydrocarbons Reaction, Journal of the American Chemical Society, 123 (2001) 81378138.

[102] A. Hwang, D. Prieto-Centurion, A. Bhan, Isotopic tracer studies of methanol-to-olefins conversion over HSAPO-34: The role of the olefins-based catalytic cycle, Journal of Catalysis, 337 (2016) 52-56.

[103] D. Mores, E. Stavitski, M.H. Kox, J. Kornatowski, U. Olsbye, B.M. Weckhuysen, Space - and Time - Resolved In - situ Spectroscopy on the Coke Formation in Molecular Sieves: Methanol - to Olefin Conversion over H - ZSM - 5 and H - SAPO - 34, Chemistry - A European Journal, 14 (2008) 11320-11327.

[104] B.A. Sexton, A.E. Hughes, D.M. Bibby, An XPS study of coke distribution on ZSM-5, Journal of Catalysis, 109 (1988) 126-131.

[105] A.T. Aguayo, A.E.S.d. Campo, A.G. Gayubo, A. Tarrío, J. Bilbao, Deactivation by coke of a catalyst based on a SAPO-34 in the transformation of methanol into olefins, Journal of Chemical Technology \& Biotechnology, 74 (1999) 315-321.

[106] P.L. Benito, A.G. Gayubo, A.T. Aguayo, M. Olazar, J. Bilbao, Deposition and Characteristics of Coke over a H-ZSM5 Zeolite-Based Catalyst in the MTG Process, Industrial \& Engineering Chemistry Research, 35 (1996) 3991-3998.

[107] S. Holmes, A. Garforth, B. Maunders, J. Dwyer, A solvent extraction method to study the location and concentration of coke formed on zeolite catalysts, Applied Catalysis A: General, 151 (1997) 355-372. 